\title{
Engaging with complexity in resilience practice
}

\author{
$\underline{\text { My M. Sellberg }}^{1}$, Allyson Quinlan $^{2}, \underline{\text { Rika Preiser }}^{3}$, Katja Malmborg $^{1}$ and Garry D. Peterson $^{1}$
}

\begin{abstract}
In a complex and turbulent world, there is heightened interest in managing for resilience. However, resilience guides, particularly those used in the development field, often lack a theoretical grounding in complex adaptive systems. There is a demand for guidance on how to operationalize complexity in applications of resilience, such as resilience assessment and planning. This study synthesizes lessons from how twelve cases of social-ecological resilience practice are engaging with complexity. We assessed how each case engaged with complexity, according to a framework of six features of complex adaptive systems. The cases are situated in a diversity of contexts, that include rural villages in Tajikistan, a Swedish municipality, Australian catchment management authorities, a Canadian coastal fishery, and the Arctic council. Our results revealed two main ways of engaging with complexity: capturing and making sense of the complexity of a social-ecological system (system complexity) and embodying complexity into the participatory process (process complexity). Our comparison demonstrates that resilience practice provides a useful approach to address system complexity by, for example, conceptualizing social-ecological interactions, identifying interactions across scales, and assessing system dynamics. Strategies related to understanding the adaptive and emergent features of complex systems were less developed and widespread. The study also revealed a set of strategies to address process complexity, such as facilitating dialogue, building networks, and designing a flexible and iterative process, showing how complexity can be embedded into the resilience assessment process. The more participatory and embedded cases of resilience practice were stronger in these process-oriented strategies. The complexity framework we used and the identified practical strategies provide a theoretically-grounded resource for managers, decision-makers, and researchers on how to engage with complexity when applying resilience in a variety of contexts, including development and landscape management.
\end{abstract}

Key Words: Case comparison; Complex adaptive systems; Practice; Social-ecological systems; Transdisciplinary

\section{INTRODUCTION}

The current Covid-19 pandemic shows how people have to navigate an increasingly turbulent and complex world (Walker et al. 2020). Human modification of the Earth system has created new dynamics and connections that are causing local ecosystems to behave in new ways, while also having an impact on distant people and places (Steffen et al. 2011, Nyström et al. 2019). A local development organization in South Africa, for example, works to strengthen water and food security, while dealing with socio-economic inequalities and apartheid legacies. At the same time, it also guides governance efforts to adapt to the ongoing effects of climate change and national and international policy decisions. In the face of this increased complexity and uncertainty, there is heightened interest in managing for resilience ( $\mathrm{Xu}$ et al. 2014). The application of this concept, through a wide range of measurement and assessment approaches, spans diverse fields linked to the sustainability sciences, such as natural resource management, international development, food security, and disaster management (Quinlan et al. 2015). Resilience guides, particularly those used in the development field, often lack a theoretical grounding in complex adaptive systems and practical guidance on how to incorporate a complexity perspective (Quinlan et al. 2015). However, a narrow, sectoral approach and simple solutions are not likely to be effective in contexts of complex sustainability challenges (Schultz et al. 2015). Navigating these new challenges that span domains and interact across scales, requires engaging with complexity and actively exploring new modes of governance that build adaptive and transformative capacities (Gunderson and Holling 2002, Chaffin et al. 2016). Operationalizing a complexity perspective is, nevertheless, challenging and there is a need for practical knowledge on how to engage with complexity in a meaningful way in contexts of resilience management, assessment, and planning (Bohensky et al. 2015, Preiser et al. 2018). A field with a tradition in applying complex adaptive systems approaches is social-ecological resilience thinking and practice.

Complex adaptive systems theory forms a conceptual point of departure for social-ecological systems research and resilience thinking (Preiser et al. 2018, Folke 2006, Folke et al. 2016, Table 1). The evolution of resilience research (Berkes and Folke 1998) has been significantly shaped by the theories and conceptual development in the field of complex adaptive systems research (Holling 1986, Levin 1998, Gunderson and Holling 2002). Resilience of social-ecological systems is commonly understood to refer to the system's capacity to cope with shocks and absorb disturbance by adapting and re-organizing while undergoing change such that it retains the same structure, function, feedbacks, and identity (Folke 2016). The concept stems from Holling's (1973) work in ecology showing that living systems can exist in multiple states or "basins of attraction". Social-ecological systems are a type of complex adaptive system that is capable of selforganization and has the capacity to learn and adapt (Folke et al. 2004). Broadly speaking, resilience thinking helps one to understand the internal factors and external influences that shape how social-ecological systems evolve over time (Gunderson and Holling 2002). A base assumption is that the interaction of systems' internal feedbacks with cross-scale dynamics can produce shifts in the organization of systems, and that diversity, surprise, and entanglement of people are key aspects for understanding or managing resilience (Gunderson and Holling 2002, Folke et al. 2010).

${ }^{1}$ Stockholm Resilience Centre, Stockholm University, ${ }^{2}$ Resilience Alliance, ${ }^{3}$ Centre for Sustainability Transitions, Stellenbosch University, South Africa 
Table 1. Glossary of key terms. Resilience and complexity are terms that are defined and interpreted in many different ways. The following definitions and key references are used in this study.

\begin{tabular}{|c|c|c|}
\hline Term & Definition & Key references \\
\hline Resilience thinking & $\begin{array}{l}\text { A conceptual framework, including the lens of social-ecological systems as complex } \\
\text { adaptive systems; concepts describing properties of such systems, such as resilience, } \\
\text { adaptability, and transformability; and a normative orientation towards sustainable } \\
\text { people-biosphere relations and human well-being. }\end{array}$ & $\begin{array}{l}\text { Walker and Salt 2006, Folke et } \\
\text { al. } 2010 \text {, Biggs et al. } 2015\end{array}$ \\
\hline Resilience practice & $\begin{array}{l}\text { Applications of resilience thinking in real-world settings, and/or at the interface of } \\
\text { science-policy-practice, including resilience assessment, planning and action. }\end{array}$ & $\begin{array}{l}\text { Resilience Alliance 2010, Walker } \\
\text { and Salt 2012, Enfors-Kautsky et } \\
\text { al. } 2018\end{array}$ \\
\hline Complexity & $\begin{array}{l}\text { A systems property that results from many diverse components that are interconnected } \\
\text { across temporal and spatial scales to produce their own pattern of behavior that is } \\
\text { dynamic and adaptive. }\end{array}$ & $\begin{array}{l}\text { Waldrop 1993, Cilliers } 1998 \text {, } \\
\text { Duit and Galaz 2008, Meadows } \\
\text { 2008, Boulton et al. } 2015\end{array}$ \\
\hline Complex adaptive systems & $\begin{array}{l}\text { Systems that contain adaptive components and capacities which allow the systems to } \\
\text { change and evolve over time in response to feedbacks and changes in the system } \\
\text { context. Complex adaptive systems have memory, so that past experiences can shape } \\
\text { future behavior, they have multiple modes of behavior, the ability to transform, and } \\
\text { have dynamic resilience. }\end{array}$ & $\begin{array}{l}\text { Holland 1995, Levin } 1998, \\
\text { Lansing 2003, Liu et al. 2007, } \\
\text { Cilliers 2008, Duit and Galaz } \\
\text { 2008, Schoon and Van der } \\
\text { Leeuw } 2015\end{array}$ \\
\hline
\end{tabular}

Resilience practice - the application of resilience thinking in realworld management and policy contexts (Table 1) — has substantially increased in the past decade. These cases of resilience assessment and resilience planning offer an opportunity to study how a a complex adaptive systems perspective translates into hands-on strategies and actions. Resilience practice builds on previous research and practical experience within the Resilience Alliance network (e.g., Holling 1973, Carpenter et al. 2001, Gunderson and Holling 2002, Walker et al. 2002, Cumming et al. 2005). Applications of resilience combine different conceptual elements for the purpose of understanding system dynamics in complex social-ecological systems. The focal unit of study or analysis is a social-ecological system, as opposed to individuals, households, communities, or cities that are the focus of other fields (e.g., psychological resilience, disaster risk resilience, community resilience, climate resilience). Although not always conducted as a participatory process, resilience practice draws on participatory approaches to learning and conceptualizing complex adaptive systems (Pretty et al. 1995, Bousquet et al. 2002, Craig et al. 2002). While there is a growing number of resilience applications, there have been few attempts made to capture the lessons learned across cases and to document and integrate these in the body of scientific literature (Sellberg et al. 2018).

In this study, we analyzed how a complexity perspective has been operationalized across twelve cases of resilience assessment and planning in different parts of the world in contexts of development and natural resource management. This paper does not present new concepts or theories, but rather contributes to bridging complexity theory and practical applications of resilience. We take a structured approach to examine this link using a framework of six features of complex adaptive systems, which capture various aspects of complex social-ecological systems. The framework is based on Preiser et al. (2018) and builds on the growing field of 'translational systems research' (Edson et al. 2017) that aims to translate theoretical concepts developed in the field of complex adaptive systems science (e.g., Wimsatt 1994, Juarrero 1999, Bohensky et al. 2015) into practical applications. So far, this field has not engaged much with applications of resilience (De Vos et al. 2019). In this study, key individuals from each case conducted a self-assessment of how they engaged with the different features of complexity. Our results do not provide in-depth knowledge on the individual cases, but an overview and illustrative examples of the different practical strategies that are used in social-ecological resilience practice for operationalizing complexity. To our knowledge, this is the first systematic analysis that describes how complexity has been operationalized across a set of case studies involving resilience assessment and planning. The strategies, tools, and insights we identified provide a theoretically-grounded resource for managers, decision-makers, and researchers on how to engage with complexity when applying resilience in a variety of contexts, including development and landscape management. Based on our findings, we discuss the strengths and weaknesses of social-ecological resilience practice in engaging complexity, reflect on the application of the framework we used, and provide recommendations for practitioners who wish to engage more deeply with complexity in their work with resilience.

\section{METHODS}

\section{Cases of resilience practice}

Our cases were selected during a workshop with resilience scholars and practitioners in South Africa, in May 2017. The participants of the workshop were connected to two organizations, both of which have the explicit aim to (among other things) apply socialecological resilience thinking in practice: the research program GRAID (Guidance for Resilience in the Anthropocene: Investments for Development), which funded the workshop, and the Resilience Alliance research network. The shared theoretical basis of these organizations enabled a selection process that was appropriate for our objective to compare cases of socialecological resilience practice. Furthermore, the selection was narrowed down to cases that were sufficiently advanced in their progress to be studied. Twelve cases from different contexts around the world (Fig. 1, Table 2) were selected, allowing us to explore the research question in diverse settings, in terms of regional variation and approaches, highlighting different ways of engaging with complexity. 
Table 2. Cases of resilience practice included in this study. The cases were initiated by different actors, academic or non-academic (see lead actors in italic), and were to varying extents co-designed by researchers and practitioners. Cases are referred to in the text using the bold part of the full case name. The order of appearance is based on when the case was initiated. The earliest case started in the beginning of the 2000s, but the majority of cases were initiated after 2010 .

\begin{tabular}{ll}
\hline \hline Case & Key actors \\
\hline $\begin{array}{l}\text { Goulburn-Broken Catchment } \\
\text { Management Authority (CMA) } \\
\text { Resilience Planning }\end{array}$ & $\begin{array}{l}\text { CSIRO (leading the first resilience } \\
\text { assessment), Goulburn-Broken CMA, } \\
\text { Australian Resilience Centre }\end{array}$ \\
& \\
& \\
Resilience Assessment in Roghun, & $\begin{array}{l}\text { Resilience Alliance, Mountain } \\
\text { Tajikistan }\end{array}$ \\
Murray Catchment Management & $\begin{array}{l}\text { Program (MSDSP) } \\
\text { Murray CMA, Australian Resilience }\end{array}$ \\
Authority (CMA) Resilience Planning & Centre, University of Tasmania
\end{tabular}

Authority (CMA) Resilience Planning Centre, University of Tasmania
Eskilstuna municipality resilience assessment of food system

Arctic Resilience Assessment (Ch. 4: What factors build or erode resilience in the Arctic?)

Resilience in the Limpopo basin programme (Resilim-O)

Natural Resource (NR) Kangaroo Island Resilience Planning

Resilience assessment in Astrid Lindgrens Hembygd (ALH)

Managing bundles of ecosystem services with multiple users in the Helge å catchment

Quantifying SES resilience in coastal Pacific Herring fishery

RAPTA pilot in Ethiopia (incl. a national level pilot with GEF, and a local level pilot with the Telecho community)

Shyamnagar resilience analysis
Eskilstuna municipality, Stockholm Resilience Centre, Albaeco

Stockholm Resilience Centre, Stockholm Environmental Institute, Arctic Council

$A W A R D$

NR Kangaroo Island, Australian Resilience Centre

Astrid Lindgrens Hembygd, Stockholm Sweden; Rural development; Resilience Centre

Stockholm Resilience Centre, Kristianstad Vattenrike Biosphere Reserve

Simon Fraser University, Heltsiuk First Nation Russia, Finland, Iceland, and indigenous representatives Development management; Climate change adaptation

Sustainability transitions; Community resilience services and multifunctional landscapes
Sweden; Local government; Food security; Sustainable development

International policy forum; Arctic council member states: Sweden, Canada, USA, Norway, Denmark, South Africa; Regional; Natural resource management; Water security

Australia; Regional; Natural resource

Sweden; Management of ecosystem

Canada; Coastal fishery; Indigenous community, culture and practices

CSIRO, Stockholm Resilience Centre, Global Environmental Facility (GEF), UNDP, Telecho community

Mangroves for the future ( $M F F$ )
Ethiopia; Sustainable development;
Tajikistan; Regional; Development

Australia; Regional; Natural resource management Food security; Land degradation

Approach

Resilience-based planning and operations (based on a participatory resilience assessment (Walker et al. 2009), and Resilience Alliance 2007, but developed into an approach to planning, Resilience Planning (Sellberg et al. 2018))

Participatory resilience assessment (based on Resilience Alliance 2007)

Resilience-based planning and operations (based on Resilience Alliance 2007, but developed into an approach to planning, Resilience Planning (Mitchell 2013, Griffith et al. 2014, Mitchell et al. 2014, Sellberg et al. 2018))

Participatory resilience assessment (based on Resilience Alliance 2010 see Sellberg et al. 2015)

Assessment of resilience framework (based on Berkes et al. 2003, and Biggs et al. 2015, see Huitric et al. 2016), includes a review of 19 different sub-cases across the Arctic. Resilience-based planning and ; operations (based on Pollard et al. 2014)

Resilience-based planning and operations (based on Resilience Alliance 2007, but developed into an approach to planning, Resilience Planning (Sellberg et al. 2018)) Participatory resilience assessment (based on Hopkins 2008, 2011, and Resilience Alliance 2010, see Sellberg et al. 2017)

Participatory resilience assessment (Malmborg et al. 2020, based on Enfors-Kautsky et al. 2018; mapping of ecosystem service bundles based on Queiroz et al. 2015)

Assessment of resilience framework (Salomon et al. 2019, based on Biggs et al. 2012, and also Resilience Alliance 2010, Cosens and Fremier 2014, Nemec et al. 2014, Allen et al. 2018)

Participatory resilience assessment (based on The Resilience, Adaptation Pathways and Transformation Assessment (RAPTA) described in $\mathrm{O}^{\circ}$ Connell et al. 2016, see also Maru et al. 2017)

Bangladesh; Ecosystem conservation; Participatory resilience assessment Sustainable development; eco-system (based on MFF Resilience Analysis dependent coastal communities $\quad$ Guidelines, informed by e.g. 
Fig. 1. Cases of resilience practice included in this study. The Arctic case covers a much larger area compared to the others, which are on a local-regional scale. Apart from the Arctic, included countries are: Australia, Bangladesh, Canada, Ethiopia, South Africa, Sweden, and Tajikistan.

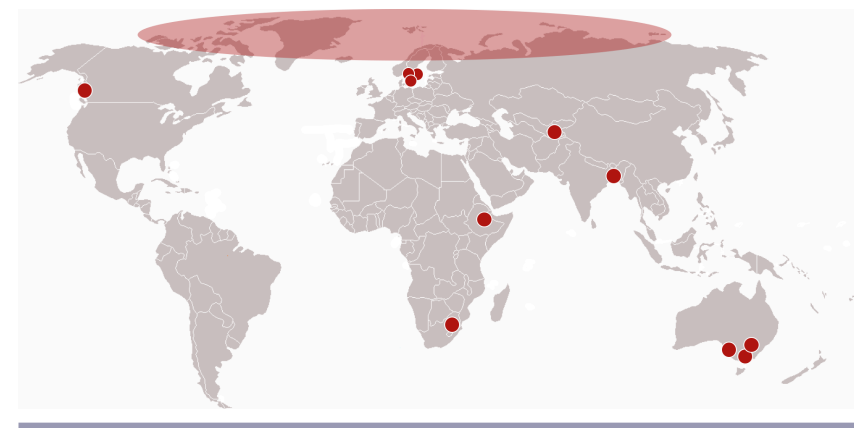

While all cases deal with the governance of social-ecological systems for environmental and social sustainability, they represent different contexts and issues. All are place-based, in that they focus on a specific geographical area, but the scope ranges from vast regions such as the Arctic, to catchment regions (GoulburnBroken, Murray, Kangaroo Island, Limpopo, and Helge å), local villages or towns and surrounding landscapes (local Ethiopia case, Tajikistan, Eskilstuna and ALH), and coastal areas (Pacific Herring, and Shyamnagar). In some cases, communities are more directly linked to and dependent on ecosystems and their resources (e.g., Tajikistan, Arctic, Pacific Herring, Shyamnagar), whereas in the Australian and Swedish cases, only a small part of the population is directly dependent on regional resources for their livelihoods. Several cases address very dynamic systems that have experienced major shifts (e.g., Shyamnagar, the Arctic, and Limpopo) while others exist in more stable contexts (e.g., the Swedish cases). The focal issues range from specific concerns, such as food security (Eskilstuna and Ethiopia) to a broader range of ecosystem services and issues tied to a particular landscape, region, or community (e.g., Goulburn-Broken, Limpopo, Shyamnagar, and Helge å).

The cases used different approaches to resilience practice that can be clustered into three overarching types: 1) Assessments of resilience frameworks, 2) Participatory resilience assessments, and 3) Resilience-based planning and operations (Table 2). These three types relate to different degrees of embeddedness within an organization. The first type includes assessments of theory-based resilience frameworks, often using literature reviews and expert surveys with a purpose to both operationalize resilience theory (Berkes et al. 2003, Biggs et al. 2015) and identify implications for policy and practice. The majority of the cases belong to the second type, participatory resilience assessments, which involve different actors in the process of assessing resilience as a stand-alone project. In the third type, resilience practice was less bound to a discrete project and more an ongoing process that gradually involved more people in the organization and influenced the operations, structure, and culture of the organization (Australian and Limpopo cases).

\section{Assessing how cases engaged with complexity}

To identify activities and strategies used in the cases to deal with the real-world complexity of social-ecological systems, we used a framework of six general features of complex adaptive systems (Preiser et al. 2018). The six features are: 1) contextual, 2) open, 3) relational, 4) dynamic, 5) adaptive, and 6) emergent (Table 3). They are based on a synthesis of leading scholars' classifications of complex adaptive system characteristics (e.g., Holland 1995, Arthur et al. 1997, Levin 1998, Cilliers 1998, Chu et al. 2003). In the absence of a unified theory of complexity, Preiser and colleagues clustered similar properties of complex adaptive systems into a typology of underlying organizing principles that are intrinsic to the features and behavior of complex adaptive systems. The framework particularly addresses the practical implications that complex adaptive systems approaches could have for social-ecological systems research. We use this framework because it operationalizes a complex adaptive systems perspective by offering a synthesis of the different features of such systems, which in turn helped us to structure our assessment. By assessing the strategies and approaches used in resilience assessment processes to engage with complexity, explicitly or implicitly, we further build on this bridge between theory and practice.

Table 3. Complexity framework. Six features of complex adaptive systems, their definitions and general implications. See guiding questions for how we assessed these features within the cases of resilience practice in Appendix 1. The table is adapted from Preiser et al. (2018).

\begin{tabular}{|c|c|c|}
\hline $\begin{array}{l}\text { Feature of } \\
\text { complex } \\
\text { adaptive } \\
\text { system }\end{array}$ & Definition & $\begin{array}{l}\text { General } \\
\text { implication }\end{array}$ \\
\hline 1. Contextual & $\begin{array}{l}\text { Components and systems have multiple } \\
\text { context dependent roles and identities. } \\
\text { Knowledge of complex adaptive systems } \\
\text { is observer-dependent and context itself } \\
\text { has agency in shaping meaning. }\end{array}$ & Context matters \\
\hline 2. Open & $\begin{array}{l}\text { Boundaries are porous with exchange of } \\
\text { matter, information and energy. Systems } \\
\text { are embedded or nested in other } \\
\text { systems, with interactions across scales } \\
\text { and domains, and have potential } \\
\text { connections to distant places. }\end{array}$ & $\begin{array}{l}\text { Consider open } \\
\text { systems }\end{array}$ \\
\hline 3. Relational & $\begin{array}{l}\text { Consisting of networks of diverse } \\
\text { components, that are often redundant, } \\
\text { and can include elements of hierarchy. }\end{array}$ & Relations matter \\
\hline 4. Dynamic & $\begin{array}{l}\text { Displaying periods of fast and slow } \\
\text { change and non-linear interactions with } \\
\text { potential thresholds or regime shifts, due } \\
\text { to enabling and constraining feedback } \\
\text { loops. Multiple trajectories or } \\
\text { equilibriums are possible. }\end{array}$ & $\begin{array}{l}\text { Assess system } \\
\text { dynamics }\end{array}$ \\
\hline 5. Adaptive & $\begin{array}{l}\text { Self-organizing and evolving, with } \\
\text { decentralized control, and has memory } \\
\text { and capacity to anticipate. }\end{array}$ & $\begin{array}{l}\text { Anticipate } \\
\text { adaptation }\end{array}$ \\
\hline 6. Emergent & $\begin{array}{l}\text { Emergent system behaviors and complex } \\
\text { cause and effect relationships, e.g. } \\
\text { meaning that same conditions can } \\
\text { produce different outcomes, small inputs } \\
\text { can have large effects, high likelihood for } \\
\text { surprise, and any intervention will have } \\
\text { unintended consequences. }\end{array}$ & $\begin{array}{l}\text { Expect complex } \\
\text { emergent } \\
\text { behavior }\end{array}$ \\
\hline
\end{tabular}


To assess the cases, we used firsthand information from a person involved in leading the resilience practice work in the case. The direct involvement of key actors in the selected case studies was a unique opportunity to gather tacit information about the cases. For this reason, we asked the case representatives themselves to conduct a reflexive analysis. A reflexive analysis is an explicit, selfaware meta-analysis that is used to compare experiences and procedures from for example participatory processes, and that requires a clear framing or framework to be reliable and transparent (Finlay 2002, Blackstock et al. 2007). In our case, the framing was informed by the six general features of complex adaptive systems (Preiser et al. 2018). We complemented the firsthand information with existing documentation about the twelve cases, including reports, policy documents, and, when available, scientific literature (see references to the literature that is publicly available in Table 2). Resilience practice cases are often not for research purposes and therefore, not published in the scientific literature. For two cases, the lead person was not available for the reflexive analysis and we then used existing documentation as our primary source of data. However, members of the author team who were familiar with those cases reviewed the information and assured that the quality of the analysis was adequate to include these cases in the study.

For each complex adaptive system feature, we developed guiding questions to interrogate the specific strategies and actions relevant for resilience practice (see Appendix 1). We used these questions as prompts to evaluate the cases, focusing specifically on identifying actions and strategies, such as methods, tools, and approaches, as well as ways of engagement. Additional ways of engaging with a particular complexity feature, not covered by the guiding questions, could also be added. We also noted if any of the six features were not addressed within a case. We did not assess the complexity of the social-ecological systems the cases were situated in. In the responses, we aimed for such a level of detail as would be useful for an external person wanting to conduct a similar process. To better understand the background and capture reflections of each case, we also included a set of general questions. These questions concerned the rationale for using the approach in that context, the advantages and disadvantages of using the approach, and the most important contributions of the assessment or process (see Appendix 1).

We analyzed the case information using thematic qualitative analysis (Patton 2002) in two rounds of coding (Charmaz 2006). First, we performed an initial coding resulting in preliminary themes of strategies across the cases, including actions, practices, and structures (such as networks or organizational structures). The three types of approaches of resilience practice also emerged from the initial coding (Table 2). We then performed a focused coding in Atlas.ti (Friese 2012) using these preliminary themes and revising them iteratively. The final codes are presented as strategies in Table 4.

\section{RESULTS}

For each complex adaptive systems feature, we describe the main strategies for engagement (Table 4) and provide examples from the different cases (see Appendix 2 for further information about the tools and concepts used by the cases, and Appendix 3 for further supporting material). Some strategies mentioned by case representatives related to multiple features. For example,
Table 4. Overview of strategies for engaging with complexity. The order of the strategies corresponds to the order they are presented in the text.

\begin{tabular}{|c|c|}
\hline $\begin{array}{l}\text { Features of } \\
\text { complex } \\
\text { adaptive } \\
\text { systems }\end{array}$ & Main strategies of cases of resilience practice \\
\hline 1. Contextual & $\begin{array}{l}\text { - Translating and adapting concepts, tools and processes to } \\
\text { local contexts; Connecting to local issues of concern; } \\
\text { Identifying locally relevant "entry points" to engage } \\
\text { participants } \\
\text { - Engaging with multiple values and definitions of the system } \\
\text { - People leading resilience practice reflecting on their own } \\
\text { roles in shaping outcomes }\end{array}$ \\
\hline 2. Open & $\begin{array}{l}\text { - Finding a useful way of defining the boundaries of the focal } \\
\text { system } \\
\text { - Identifying external drivers of change and interactions } \\
\text { across scales (e.g. above and below the focal system) } \\
\text { - Engaging key higher levels of governance and external } \\
\text { actors who shape system context and dynamics }\end{array}$ \\
\hline 3. Relational & $\begin{array}{l}\text { - Building relations between science and practice and } \\
\text { integrating different disciplines and types of knowledge } \\
\text { - Highlighting and conceptualizing connections between } \\
\text { people and the biosphere (e.g. social-ecological systems); } \\
\text { Mapping social networks and governance relationships } \\
\text { - Facilitating dialogue and building networks between } \\
\text { different actors; Bringing actors together to develop } \\
\text { coordinated actions }\end{array}$ \\
\hline 4. Dynamic & $\begin{array}{l}\text { - Identifying historical changes and trends } \\
\text { - Considering potential thresholds of concern and possible } \\
\text { regime shifts } \\
\text { - Conceptualizing and modeling system interactions and } \\
\text { feedbacks } \\
\text { - Developing alternative future scenarios and pathways }\end{array}$ \\
\hline 5. Adaptive & $\begin{array}{l}\text { - Designing a flexible and iterative process; Enhancing } \\
\text { system understanding among participants } \\
\text { - Building a learning culture within the project, the approach } \\
\text { or in the organization; Building capacity of external actors in } \\
\text { planning, monitoring and learning } \\
\text { - Using theory-based resilience assessment framework } \\
\text { (including assessing key principles or attributes of resilience } \\
\text { and adaptive capacity) }\end{array}$ \\
\hline 6. Emergent & $\begin{array}{l}\text { - Enabling the creation of (multiple and/or shared) narratives } \\
\text { - Enabling a broader scope and reinforcing local perspectives } \\
\text { - Allowing for emergence through trust-building and a } \\
\text { flexible process }\end{array}$ \\
\hline
\end{tabular}

"engaging key higher levels of governance and external actors" concerns both relational and open. However, we placed each strategy only under the most relevant feature to minimize overlap in the text.

\section{Contextual}

The contextual feature means that roles, identities and knowledge of complex adaptive systems are context-dependent and depend on the perspective of the observer (Table 3). A key strategy to deal with this feature was to translate and adapt the process and issues to the local context and actors, rather than focusing on predecided issues and applying a blueprint approach. All cases considered their context, but in different ways. In the Australian cases, different sub-systems or "local landscapes" were identified, differentiating priorities and implementation strategies, and supporting the development of local plans together with local actors. Two of the participatory cases identified a locally relevant 
"entry point" to start engaging participants. The Limpopo case described that when developing systems diagrams collaboratively, they "find a hooking point that matters for people", such as food, health, or water. Helge å found ecosystem services to be a useful hooking point since the concept was gaining attention in the Swedish governance context. Furthermore, by including a diverse set of services, the ecosystem service bundles acknowledged many different values in the landscape and became a concept that the diverse group of participants could unite around. This helped different stakeholders feel welcome and facilitated a dialogue between them (see also relational). The Arctic and Pacific Herring cases also combined their theory-based frameworks with locally defined resilience outcomes (Arctic) or locally relevant metrics and management eras (Pacific Herring).

Another key strategy cases used to acknowledge that knowledge is context-dependent was to consider multiple values and definitions of the system. For example, in the participatory cases, this meant inviting a diversity of actors and carefully eliciting their different perspectives in workshops (e.g., Helge å, Eskilstuna, Tajikistan, ALH). In cases where inequality was a key concern these practices were generally more sophisticated. The Tajikistan, Ethiopia, and Shyamnagar cases encouraged perspectives of less powerful groups, such as women, youth, and landless people, for example by meeting with different actor groups separately, and by including "benefit for landless people and women" as a criterion for assessing proposed activities. Ethiopia and Shyamnagar also articulated multiple and complementary pathways of change.

In our complexity framework, knowledge is considered observerdependent and has agency in shaping meaning (Table 3). However, practitioners seldom reported explicitly reflecting on their own roles in shaping outcomes. Only two cases had documented doing this, by reflecting on project limitations (Ethiopia) or evaluating the usefulness of the approach (ALH).

\section{Open}

The open feature highlights how system boundaries are porous and that systems are embedded or nested in other systems, with interactions across scales and domains (Table 3). Because systems are open, the cases needed to find a useful way of defining their focal systems. Some focused on a local community, while others used administrative boundaries of a municipality or catchment management authority. Helge å, Shyamnagar, and Limpopo used both administrative and biophysical boundaries, such as catchments, rivers, and forests, which partially overlapped. System definitions were driven by different factors, such as the mandate of the organization, the perceived sphere of influence of participants, key issues of concern, and the scale and resolution of accessible data. For example, the Pacific Herring case used " $a$ region that loosely corresponded to the traditional territory (including fishing areas) of the Heltsiuk First Nation", as a way of supporting the Heltsiuk First Nation, who "have some authority over their traditional territory and are trying to reassert this authority to gain more power in how fisheries are managed." This definition corresponded to the goals of their resilience practice.

Once the system had been defined, all the cases identified external drivers and cross-scale interactions, but each using different tools and exercises (Appendix 2). Sometimes consideration of external drivers and scales above and below the focal system were part of exercises to explore system dynamics, such as historical timelines and systems diagrams. Others performed specific scoping exercises, for example using V-STEEP, which captures factors across six dimensions: values, social, technological, ecological, economic, and political (Biggs and Rogers 2003, Pollard et al. 2014). Some cases described a lack of influence over critical drivers, for example, Arctic communities' influence over climate change, which made participants feel overwhelmed or powerless. Strategies to deal with this were to focus on the sphere of influence (Limpopo) and to connect to higher-level, more influential actors (see below). Most cases identified climate change as a key driver influencing their system, but ALH and Kangaroo Island stood out in that they also addressed the responsibility to decrease local carbon emissions.

Some participatory resilience assessments addressed the open feature by involving higher levels of governance and other key actors shaping their system context (ALH, Eskilstuna, Ethiopia, Helge å). Depending on what was deemed appropriate for their context, higher-level actors were involved in separate meetings or as part of the resilience workshops. Involving these actors seemed to increase a sense of agency or legitimacy. In Eskilstuna, a preworkshop with actors across organizational levels (e.g., national, county, municipality) supported the municipality to take on the issue of food security, even though they did not have a clear formal mandate.

\section{Relational}

Relational implies that complex adaptive systems consist of networks of diverse components and that relations matter (Table 3). By bridging different disciplines and types of knowledge, all the cases were building relations across research fields, between science and practice, and sometimes also with policy. Certain cases pointed out how existing relationships and partnerships between science and practice were part of enabling resilience practice in the first place (e.g., Pacific Herring, Helge å) and that "this trust would have been reinforced by continuing a long-term collaborative relationship" (Pacific Herring). Five cases particularly highlighted the concept of social-ecological systems as a way to integrate different disciplines and types of knowledge, for example, the Arctic case:

"We use the concept of social-ecological systems as a framework for integrating the diverse types of knowledge needed to understand the interactions taking place in the Arctic,..." (Arctic Council 2016: $x i)$.

All cases also highlighted connections between people and the biosphere by identifying system components across ecological and social dimensions. Eleven cases conceptualized peoplebiosphere connections using different tools and concepts, such as ecosystem services, system diagrams, and conceptual models of social-ecological systems (Appendix 2). In addition, four cases mapped either social networks or governance relationships, roles and responsibilities.

Apart from mapping relations, all the participatory cases were facilitating dialogue and building networks between different actors. Helge å and Limpopo used collaborative development of system diagrams to facilitate dialogues (Appendix 2). A few cases reported building bridges between different groups, for example, 
those interested in environmental sustainability and those more interested in traditional forms of development (e.g., ALH, Kangaroo Island). The strategy of bringing actors together in coordinated action was most important for the cases of resiliencebased planning and operations (i.e., Goulburn-Broken, Murray, Kangaroo Island, Limpopo). These organizations put effort into developing partnerships across different actors and levels of governance. The Limpopo case representative described that " $a$ lot of my role is seeing connections between things" and that the organization "spends a lot of time to build trust around a common practice".

\section{Dynamic}

The dynamic feature captures the idea that complex adaptive systems exhibit non-linear change with potential thresholds, due to underlying feedback mechanisms. To assess system dynamics, cases highlighted different key tools: historical timelines, thresholds, system diagrams, and scenarios (Table 4). Four cases emphasized the development of historical timelines (Eskilstuna, Pacific Herring, Shyamnagar, Tajikistan). This activity highlighted the loss of resilience over time, but also potential opportunities in recent trends, and ultimately underscored a need to build capacity in the system and reverse the trend of declining resilience. Shyamnagar described the most powerful tool to challenge people's way of thinking as: "Any tool that visualizes the trends, drivers, and pressure (e.g., timeline) helps people to contextualize and think out of the box."

Six cases focused on potential thresholds and regime shifts. However, several reported struggling with applying the concept because of pedagogical challenges, lack, of time or risk of simplifying social aspects too much. For example, Limpopo acknowledged existing thresholds in ecological systems, but in multi-layered social-ecological systems with social and political dimensions, thresholds are more "morphed and blurry", which made it difficult to define the "change state". Despite these challenges, several cases facilitated discussions of potential thresholds in workshops, using different tools and heuristics (Appendix 2). One application was to consider potential thresholds, rather than trying to measure exact threshold levels (Eskilstuna) and focusing on specific sub-systems, such as terrestrial landscape health, rather than the region as a whole (Kangaroo Island). Four cases used potentially critical thresholds to direct monitoring and management since these are likely to influence the future state of the system (Limpopo, Murray, Ethiopia, Goulburn-Broken). Goulburn-Broken took this further by incorporating critical thresholds in the organizations' risk register, which the Board has to address as part of their accountability.

To identify system interactions and feedbacks, the most common approach was to develop system diagrams, such as influence diagrams or causal loop diagrams (Appendix 2). Murray, Helge å and Limpopo emphasized developing system diagrams collaboratively as a key tool. Helge å reported how the exercise highlighted system dynamics and interactions "that were not obvious at a first glance, but that have become clear when we puzzled together the different areas of expertise."

The fourth key tool to assess system dynamics was to developed alternative future scenarios or pathways (Appendix 2). The scenarios served to explore uncertainty of key drivers and management decisions (Shyamnagar), implications of different sets of interventions (Ethiopia), different responses to climate change (Kangaroo Island), and a shared positive vision or desirable pathway (Shyamnagar, Eskilstuna, Helge å).

\section{Adaptive}

The adaptive feature means that complex adaptive systems are self-organizing and evolving, have memory, and capacity to learn while responding to change (Table 3). Different types of cases highlighted different strategies to deal with this feature. For several of the participatory cases, a flexible and iterative process design was key. In Helge å, the outcome of each exercise was synthesized between workshops and discussed again with participants. If needed, results were then updated before being used as building blocks in the next steps of the process. In practice, this meant that every final output was iterated two or three times with participants, enabling learning and a more adaptive and responsive process. Both the participatory cases and resiliencebased operations emphasized fostering learning experiences among participants, particularly to enhance systems understanding. Learning was supported by interactive workshop exercises, facilitated dialogues between diverse perspectives, social learning processes (e.g., Limpopo and Murray based on: Brown and Lambert 2013, Engeström 2016), and by having time for iterations.

For the cases of resilience-based planning and operations, building a culture of learning was a key strategy. The Australian organizations planned for how to update their strategies when necessary and regularly re-evaluate their goals and visions, by incorporating ideas of triple-loop learning (Tosey et al. 2011), adaptive management (Walters 1986), and adaptive governance (Folke et al. 2005) (Appendix 2). They also structured how they organized and updated evidence and assumptions underlying their strategies. Previous research shows signs of organizational change in two of these organizations (Goulburn-Broken and Murray) such as the emergence of a shared language and a strengthened capacity for continuous planning (Mitchell 2013, Sellberg et al. 2018). AWARD, the organization leading the Limpopo case, developed their own monitoring and evaluation system to guide the way staff work with projects. They were explicitly trying to build a culture around learning from failures and unintended consequences:

"if something emerges - it's ok, it's endorsed with the way AWARD works, the narration around it is much more important. For example, if a workshop didn't happen - why didn't it happen, what can we learn from that?"

The resilience-based planning and operations, as well as the Ethiopia case, were also building capacity of external actors, for example by forming learning networks around specific areas where participants could learn from each other.

For the assessments of resilience frameworks, the frameworks themselves were a key strategy to address the adaptive feature. Pacific Herring used Biggs et al.'s (2015) seven resilience principles and Arctic the four categories of resilience-building strategies by Berkes et al. (2003). These frameworks include key principles or attributes of resilience, representing a general capacity to adapt and navigate change. These cases, including Limpopo, used quantitative or qualitative data to assess how certain attributes 
are important for resilience (Arctic), how they have changed over time (Pacific Herring), or how they could change with different scenarios (Limpopo).

\section{Emergent}

The emergent feature implies expecting complex emergent behavior, including surprising outcomes and unintended consequences (Table 3). This category included experiences of positive emergent outcomes of resilience practice, as well as strategies to adapt to surprising external events. An emergent outcome across several cases was a shared narrative, motivating a need to change or outlining an overarching aspiration. For example, the Ethiopia case described the,

"emergence of a shared narrative that suggests taking pressure off the environment by engaging with livelihood strategies less dependent on natural resources." (Maru et al. 2017:69)

With these shared aspirations, participants could then collaborate despite having different and sometimes conflicting interests and priorities. Different tools, such as resilience principles, timelines, scenarios, and system diagrams, were key in articulating a narrative (see dynamic, adaptive). Dialogue and different forms of engagement were important for the narrative to become shared and owned by the participants (see contextual, relational).

Other emergent outcomes included a broader scope of operations, reinforcement of local perspectives, and systems understanding. The national Ethiopia case addressed a wider range of drivers and activities related to land degradation and food security, compared to the usual focus on natural resource management (see open), which highlighted critical variables and activities needed to address the root causes of problems. The broader scope also encouraged the organization to collaborate with actors across organizational boundaries and sectors (see relational). In the Arctic and Pacific Herring cases, the involvement of researchers helped to translate the knowledge of indigenous and local communities for other contexts, such as bureaucratic processes (see contextual, open). The Pacific Herring case representative explained that the "...collaborators wanted their case documented in peer-reviewed literature so that they could refer to it." Some cases also reported signs of increased understanding of systems among participants, such as understanding connections between issues (see adaptive). The Tajikistan representative described that,

"one positive unplanned outcome was a discussion on girls' education and birth control options with the community leader after making the connection between dwindling arable land, a growing population, crop yields, and employment opportunities."

A key strategy to allow for emergence, in general, was a flexible process design, allowing for iterations, experimentation, reflection, and adaptations to local contexts (contextual, adaptive). This also helped to deal with surprising, external changes. For example, Tajikistan experienced the major shock of "the global economic crisis and mass return of workers from Russia to the rural villages", which they dealt with by including it in the follow-up workshop with their communities and in their analysis. Limpopo highlighted how a culture of learning and a flexible project governance allowed for emergence, for example through having flexible goals. Moreover, existing relations and trust sometimes enabled positive emergent outcomes, such as coordinated action.

\section{DISCUSSION}

\section{Resilience practice as an approach for understanding complex} adaptive systems

Our results show that resilience practice provides a useful approach to understanding the complexity of social-ecological systems, including governance system dynamics. While it is not the only approach that does this, it has certain strengths that are highlighted in the conceptual framework of resilience thinking, such as people-biosphere connections, dynamics of change, and interactions across scales (Gunderson and Holling 2002, Berkes et al. 2003). These are key features in the early guides to resilience practice (Walker et al. 2002, Resilience Alliance 2007). In the twelve cases of resilience practice analyzed in this study, these strengths emerged as core strategies that were employed across the cases and relate to the first four complex adaptive system features (Table 4). These strategies include: adapting the approach to local contexts (contextual), identifying cross-scale interactions (open), conceptualizing social-ecological interactions (relational), and a rich variety of tools and methods to capture system dynamics (dynamic). While the cases highlight similar strategies for the first three features, they emphasize different key tools in understanding system dynamics, such as potential thresholds of concern or alternative future scenarios. These core strategies mainly concerned capturing the complexity of the socialecological system to be governed ("system complexity") and making sense of it through meaningful simplifications (Fig. 2). Often, the people leading the assessment process did not know beforehand which tool would provide the most insight into their system, underscoring how useful it is to have a suite of tools available and the flexibility to experiment with what works best in a particular context. All the cases shaped these strategies into situated practices according to the constraints and opportunities of each case, for example by incorporating them into the governance structures of the organization, as in the Shyamnagar and Goulburn-Broken cases. Being skilled at adapting the concepts and methods to the particular place and purpose is a key advantage when engaging with complexity.

Fig. 2. Operationalizing complexity. The cases of resilience practice operationalized complexity both through tools and concepts to better understand and capture the complexity of a social-ecological system ("system complexity"), and through designing a participatory process that embodied different features of complex adaptive systems ("process complexity").

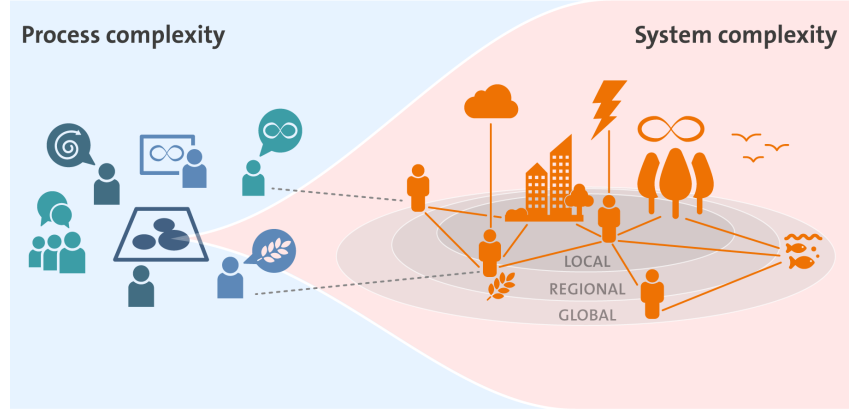


The analysis also revealed areas of understanding complexity that could be further developed within resilience practice to shed light on additional aspects of social-ecological systems. These areas include: assessing the adaptive capacity, general resilience or option space of a social-ecological system (adaptive), mapping social and governance relations (relational), and understanding processes of emergence (emergent). For the first two, a few cases adopted these strategies, but a majority of the cases did not. These are areas that have been limited in resilience practice, but have been given more attention in recent guides (e.g., Enfors-Kautsky et al. 2018). Formal governance structures and cross-scale interactions within the legal system are important to account for when assessing the current resilience and past development trajectory of a social-ecological system (Gunderson et al. 2017). A thorough analysis of the legal system and the extent to which it influences resilience is generally beyond the scope of the sort of resilience cases that have been analyzed in this study. However, more recent guides in resilience practice, such as the Wayfinder (Enfors-Kautsky et al. 2018), include concepts and tools to help in articulating the agency of different actors whilst taking into account existing laws and regulations at different scales. These types of exercises help participants become more aware of existing flexibilities within the governance system (Garmestani et al. 2019), providing them with tools and language to strategically navigate within their respective contexts.

While the emergent feature partly overlapped with the adaptive feature, as such it was not explicitly addressed by the cases. Compared to previous systems approaches, a complex adaptive systems perspective emphasizes emergent and adaptive aspects more (Hartvigsen et al. 1998). In the theory and basic research of resilience thinking, the use of methods that highlight emergence, such as participatory narrative inquiry, is more recent than those that capture other characteristics of complex adaptive systems (Preiser et al. 2018). Methods to capture the feature of emergence, for example, agent-based modelling (Railsback and Grimm 2011), are yet to be applied within mainstream resilience practice, but see e.g., Schlüter and Pahl-Wostl (2007). Insights from other related approaches and research fields could also contribute to strengthen the ability of resilience practice to capture these features. More specifically, recent developments in assessing pathway diversity offer a promising approach to quantifying resilience in a way that roughly relates to a system's option space, yet integrates potential feedbacks from actions, thus embedding emergent and adaptive features of complex systems (Lade et al. 2020). Similarly, the increasing body of scholarship on sustainability transformations within social-ecological resilience research (Westley et al. 2013, Olsson et al. 2014, Lindow 2017, Horcea-Milcu et al. 2020, Lam et al. 2020) could help shed light on social relations and complex societal change processes with emergent outcomes. Recent research could also help to better acknowledge power and situated agency in social-ecological systems (Boonstra 2016, Järnberg et al. 2018).

\section{Embodying complexity in the participatory process}

An additional set of strategies relating to process design emerged in our analysis of the twelve resilience practice cases. These were strategies that focus on operationalizing complexity in the assessment, governance, or learning process - "process complexity" (Fig. 2). This meant viewing the process as a complex system in itself, where outcomes cannot be controlled but only facilitated, enabled, and co-created with participants (Wall et al. 2017, Pereira et al. 2020). Not all systemic approaches integrate a complexity perspective into aspects of process design, facilitation and engagement (Boulton et al. 2015). Several of the cases of resilience practice, however, had adopted such strategies.

These strategies particularly promoted relations, trust, and learning as instrumental to operationalize a complexity perspective, and mostly relate to the features of relational, adaptive, and emergent. By emphasizing trust-building, the process design becomes an embodiment of how complex adaptive systems are relational. Factors such as trust and relations between the case participants were both described as emergent outcomes of collaboration and dialogue and as enabling a flexible process and coordinated action (see also e.g., Freeth and Drimie 2016). A flexible and iterative process design also enabled learning, which is important for adaptive capacity both in organizations and in the management procedures that they implement (Schultz et al. 2015). Emergence in the context of process design relates to enabling positive emergent process outcomes that could help navigate change in complex settings (Enfors-Kautsky et al. 2021). Several of the participatory resilience assessments described emergent outcomes, such as a shared narrative and increased system understanding, which sometimes paved the way for coordinated actions and capacity building. Apart from these features, aspects of contextual and open, such as engaging with multiple values and involving higher-level actors in the process, are also related to process design.

Of the three different types of resilience practice outlined in the Methods section (Table 2), both the participatory resilience assessments and resilience-based planning and operations are strongest in these process-oriented complexity features. We saw a higher potential for positive emergent outcomes, for example, in long-term, participatory and more embedded approaches to resilience practice. These types of approaches imply a higher degree of participation and, for the resilience-based planning and operations, more ownership from the organization involved. Therefore, they also require a larger organizational commitment and more resources for the engagement process and to challenge existing ways of planning and operating (Sellberg et al. 2018). The complexity features used in this study (Table 3 ) could potentially be translated into design principles for participatory processes that enable desirable emergent outcomes, such as learning experiences and relations. However, when operationalizing the emergent feature, other features of good governance also have to be taken into account, such as accountability (Hahn 2011). Overly flexible governance processes risk being experienced as illegitimate, unfair, and disruptive if they are not balanced with stability (Craig et al. 2017).

While the strengths discussed for understanding system complexity originate from conceptual frameworks and have been translated into tools and methods, the strategies related to process complexity come from practice and have been built up through practical experiences of applying resilience thinking. Since these experiences have evolved over time, the articulation of how to transfer strategies between contexts is better captured in later versions of resilience practice guides, such as Wayfinder (EnforsKautsky et al. 2018). Resilience practice could be further strengthened by adopting insights from other related approaches 
that address aspects of process complexity, such as social learning (e.g., Brown and Lambert 2013, Engeström 2016), which already was adopted by the Murray and Limpopo cases, and how to develop narratives (e.g., Leach et al. 2010, Kurz 2014, Ingram et al. 2015). It would also be beneficial to further develop and integrate methods for encompassing multiple knowledge systems into resilience practice (Tengö et al. 2014, Falardeau et al. 2018) and how to enable adaptive processes of governance and comanagement (Walters 1986, Armitage et al. 2009, Schultz et al. 2015).

Reflecting on our framework of complex adaptive system features After discussing the lessons for resilience practice, we will now briefly reflect on the framework of complex adaptive system features used in this study and how it could be applied. A complex adaptive systems perspective calls for a certain modesty of the frameworks and models used, since they are necessarily partial (Preiser et al. 2018). The framework we used focuses on systemlevel properties rather than on the agency of individuals. Even though it does include the nested characteristic of systems interacting across scales (see open, Table 3), more emphasis on the agency of networks and initiatives across scales could help to better understand the transformative capacity of governance systems and of social-ecological systems (Westley et al. 2013, Chaffin et al. 2016, Bennett et al. 2015, Lade et al. 2020). Complex sustainability challenges often call for transformative change and facilitating deliberate and positive change is becoming an increasingly important aspiration of resilience practice (EnforsKautsky et al. 2018). This motivates including transformative capacities as, perhaps not a key feature, but at least a key interest when navigating complex adaptive systems. We also have not explicitly discussed the ethical and normative implications of a complex adaptive systems perspective that Preiser et al. (2018) highlight, such as the call for "more inclusive and integrative modes of engaging with real-world problems" that comes with an acknowledgment of interdependence. Even though, they were often part of the underlying motivations and practices of the resilience assessment cases we studied, an explicit discussion of ethical implications could support the kind of reflexivity we hope to encourage.

\section{Practical recommendations}

Resilience practitioners might benefit from the findings of this paper, as we hope to have highlighted how resilience practice can incorporate a complexity perspective. As discussed, our results do not provide a prescription or a blueprint for how practitioners should go about designing particular assessments or processes in particular contexts. Instead, we hope that this paper can provide a resource bank with examples where one can gain new ideas and new entry points to search for more in-depth guidance on a specific tool or approach that is found interesting. Appendix 2 provides references to specific tools and concepts that have been used in the case studies of this analysis. The examples presented there come from a diversity of places, mainly focusing on the local and regional scale, and in contexts of natural resource management and development. Before being applied elsewhere, therefore, adjustments might need to be made to better fit the new context. The six features are complementary and help structure an understanding for complex adaptive systems. The examples of tools, exercises and aspects of process design connected to each feature provide a means to operationalize complexity in real- world settings, such as within the scope of a resilience assessment process. The guiding questions in Appendix 1 may also be used to aid reflection and inspiration when developing new tools and exercises with a specific feature in mind, or when evaluating an already ongoing or completed process. While addressing the six features of complex adaptive systems might not be sufficient to deal with complexity in all contexts, we are confident that this framework can strengthen and broaden existing work in resilience practice.

\section{CONCLUSIONS}

This study has contributed with practical guidance and examples of how to operationalize complexity, by synthesizing lessons from twelve cases of social-ecological resilience practice situated in diverse settings. We used a framework of six features of complex adaptive systems to assess how the cases engaged with complexity. Based on our results, we highlight two areas of operationalizing a complexity perspective: understanding the complexity of a social-ecological system (system complexity), and embodying complexity into the participatory process (process complexity). Our findings reveal core strategies across cases in addressing system complexity, such as conceptualizing social-ecological interactions and assessing system dynamics, showing a strength in resilience practice in helping to understand and make sense of complexity in a context of social-ecological systems. Potential areas to improve are implementing methods for assessing adaptive capacity and understanding processes of emergence. Several cases, particularly the more long-term, participatory, and embedded ones, also addressed process complexity by adopting strategies that incorporated features of complex adaptive systems into the process design. These strategies included designing a flexible and iterative process that enabled trust-building, relations, and learning experiences. Ways to further strengthen aspects of process complexity are, for example, to further integrate methods and insights from research on social learning, encompassing multiple knowledge systems, and how to develop narratives.

Resilience and sustainability practitioners working from a complex adaptive systems perspective can benefit from both the framework and the identified practical strategies in the design and ongoing practice of resilience assessment and planning. The complexity framework and guiding questions are useful for a deeper and more systematic reflection on different aspects of complexity - both of social-ecological systems and of the collective learning process and your own role in it. The practical strategies identified in this study can provide practitioners with a set of tools to better capture and engage with the complexity of the places they are working within. The framework and related identified strategies could also help practitioners design participatory processes in complex settings that enable desirable emergent outcomes, such as learning experiences, relations, shared narratives, and coordinated actions.

Responses to this article can be read online at: https://www.ecologyandsociety.org/issues/responses. php/12311 


\section{Acknowledgments:}

We are very grateful for having had the opportunity to collaborate with the resilience practitioners and scholars that took part in this study. Particular thanks to Paul Ryan and Sharon Pollard for contributing with their expertise to the case assessment. We thank Elin Enfors-Kautsky and Cibele Queiroz for useful comments on the manuscript and Vanessa Masterson for helpful input in the initial stages of this study. This research was conducted under the SEEN project (Social-Ecological dynamics of Ecosystem services in the Norrström basin), funded by the Swedish Research Council Formas (grant number 2012-1058), and the GRAID programme, funded by the Swedish International Development Cooperation Agency, SIDA. This research contributes to the Program on Ecosystem Change and Society (www.pecs-science.org). The Stockholm Resilience Centre was at the time funded by Mistra, the Foundation for Strategic Environmental Research.

\section{Data Availability:}

Relevant qualitative data underlying the findings presented in the paper is available in appendices.

\section{LITERATURE CITED}

Allen, C. R., H. E. Birge, D. G. Angeler, C. A. (Tony) Arnold, B. C. Chaffin, D. A. DeCaro, A. S. Garmestani, and L. Gunderson. 2018. Quantifying uncertainty and trade-offs in resilience assessments. Ecology and Society 23(1):3. https://doi.org/10.5751/ ES-09920-230103

Arctic Council. 2016. Arctic resilience report. Carson, M., and G. D. Peterson, editors. Stockholm Environment Institute, and Stockholm Resilience Centre, Stockholm, Sweden. http://www. arctic-council.org/arr.

Armitage, D. R., R. Plummer, F. Berkes, R. I. Arthur, A. T. Charles, I. J Davidson-Hunt, A. P. Diduck, N. C. Doubleday, D. S. Johnson, M. Marschke, P. McConney, E. W. Pinkerton, and E. K. Wollenberg. 2009. Adaptive co-management for social-ecological complexity. Frontiers in Ecology and the Environment 7(2):95-102. https://doi.org/10.1890/070089

Arthur, W. B., S. Durlauf, and D. Lane. 1997. Introduction. Pages 1-14 in W. B. Arthur, S. N. Durlauf, and D. Lane, editors. The economy as an evolving complex system II. Addison-Wesley, Reading, Massachusetts, USA.

Bennett, E. M., M. Solan, R. Biggs, T. McPhearson, A. V. Norström, P. Olsson, L. Pereira, G. D. Peterson, C. RaudseppHearne, F. Biermann, S. R. Carpenter, E. C. Ellis, T. Hichert, V. Galaz, M. Lahsen, M. Milkoreit, B. Martin López, K. A. Nicholas, R. Preiser, G. Vince, J. M. Vervoort, and J. Xu. 2016. Bright spots: seeds of a good Anthropocene. Frontiers in Ecolology and the Environment 14 (8):441-448. https://doi.org/10.1002/fee.1309

Berkes, F., and C. Folke, editors. 1998. Linking social and ecological systems. Cambridge University Press, Cambridge, UK.

Berkes, F., J. Colding, and C. Folke, editors. 2003. Navigating social-ecological systems: building resilience for complexity and change. Cambridge University Press, Cambridge, UK. https://doi. org/10.1017/CBO9780511541957

Biggs, H., and K. H. Rogers. 2003. An adaptive system to link science, monitoring and management in practice. Pages 59-80 in J. T. D. Toit, K. H. Rogers, and H. C. Biggs, editors. The Kruger experience: ecology and management of savanna heterogeneity. Island, Washington, D.C., USA.

Biggs, R., M. Schlüter, D. Biggs, E. L. Bohensky, S. BurnSilver, G. Cundill, V. Dakos, T. M. Daw, L. S. Evans, K. Kotschy, A. M. Leitch, C. Meek, A. Quinlan, C. Raudsepp-Hearne, M. D. Robards, M. L. Schoon, L. Schultz, and P. C. West. 2012. Toward principles for enhancing the resilience of ecosystem services. Annual Review of Environment and Resources 37(1):421-448. https://doi.org/10.1146/annurev-environ-051211-123836

Biggs, R., M. Schlüter, and M. L. Schoon, editors. 2015. Principles for building resilience: sustaining ecosystem services in socialecological systems. Cambridge University Press, Cambridge, UK.

Blackstock, K. L., G. J. Kelly, and B. L. Horsey. 2007. Developing and applying a framework to evaluate participatory research for sustainability. Ecological Economics 60:726-742. https://doi. org/10.1016/j.ecolecon.2006.05.014

Bohensky, E. L., L. S. Evans, J. M. Andries, D. Biggs and C. Fabricius. 2015. Principle 4 - Foster complex adaptive systems thinking. Pages 142-173 in R. Biggs, M. Schlüter and M. L. Schoon, editors. 2015. Principles for Building Resilience. Cambridge University Press.

Boonstra, W. J. 2016. Conceptualizing power to study socialecological interactions. Ecology and Society 21(1):21. https://doi. org/10.5751/ES-07966-210121

Boulton, J. G., P. M. Allen, and C. Bowman. 2015. Embracing complexity: strategic perspectives for an age of turbulence. Oxford University Press, Oxford, UK. https://doi.org/10.1093/acprof: oso/9780199565252.001.0001

Bousquet, F., O. Barreteau, P. D’Aquino, M. Etienne, S. Boissau, S. Aubert, C. Le Page, D. Babin, and J.-C. Castella. 2002. Multiagent systems and role games: collective learning processes for ecosystem management. Pages 248-285 in M. A. Janssen, editor. Complexity and ecosystem management: the theory and practice of multi-agent systems. Edward Elgar Publishers, Cheltenham, UK/ Northampton, Massachussetts, USA.

Brown, V. A., and J. A. Lambert. 2013. Collective learning for transformational change: a guide to collaborative action. Earthscan, London, UK. https://doi.org/10.4324/9780203105672

Carpenter, S., B. Walker, J. M. Anderies, and N. Abel. 2001. From metaphor to measurement: resilience of what to what? Ecosystems 4(8):765-781. https://doi.org/10.1007/s10021-001-0045-9

Chaffin, B. C., A.S . Garmestani, L. H. Gunderson, M. H. Benson, D. G. Angeler, C. A. Arnold, B. Cosens, R. K. Craig, J. B. Ruhl, and C. R. Allen. 2016. Transformative environmental governance. Annual Review of Environment and Resources 41:399-423. https:// doi.org/10.1146/annurev-environ-110615-085817

Charmaz, K. 2006. Constructing grounded theory: a practical guide through qualitative analysis. Sage Publications, Thousand Oaks, USA. 
Chu, D., R. Strand, and R. Fjelland. 2003. Theories of complexity: common denominators of complex systems. Complexity 8(3):19-30. https://doi.org/10.1002/cplx.10059

Cilliers, P. 1998. Complexity and postmodernism: understanding complex systems. Routledge, London, UK.

Cilliers, P. 2008. Complexity theory as a general framework for sustainability science. Pages 39-57 in M. Burns and A. Weaver, editors. Exploring sustainability science. A southern African perspective. AFRICAN SUN MeDIA, Stellenbosch, South Africa.

Cosens, B., and A. Fremier. 2014. Assessing system resilience and ecosystem services in large river basins: a case study on the Columbia River Basin. Idaho Law Review 51.

Craig, W. J., T. M. Harris, and D. Weiner, editors. 2002. Community participation and geographic information systems. Taylor and Francis, London, UK.

Craig, R. K., A. S. Garmestani, C. R. Allen, C. A. Arnold, H. Birgé, D. A. DeCaro, A. K. Fremier, H. Gosnell, and E. Schlager. 2017. Balancing stability and flexibility in adaptive governance: an analysis of tools available in U.S. environmental law. Ecology and Society 22(2):3. https://doi.org/10.5751/es-08983-220203

Cumming, G. S., G. Barnes, S. Perz, M. Schmink, K. E. Sieving, J. Southworth, M. Binford, R. D. Holt, C. Stickler, and T. Van Holt. 2005. An exploratory framework for the empirical measurement of resilience. Ecosystems 8(8):975-987. https://doi. org/10.1007/s10021-005-0129-Z

De Vos, A., R. Biggs, and R. Preiser. 2019. Methods for understanding social-ecological systems: a review of place-based studies. Ecology and Society 24(4):16. https://doi.org/10.5751/ ES-11236-240416

Duit, A., and V. Galaz. 2008. Governance and complexity emerging issues for governance theory. Governance 21 (3):311-335. https://doi.org/10.1111/j.1468-0491.2008.00402.x

Edson, M. C., P. Buckle Henning, and S. Sankaran. 2017. A guide to systems research philosophy, processes and practice. Springer Science \& Business Media, Singapore.

Enfors-Kautsky, E., L. Järnberg, A. Quinlan, and P. Ryan. 2018. Wayfinder: a resilience guide for navigating towards sustainable futures. GRAID programme, Stockholm Resilience Center. www. wayfinder.earth.

Enfors-Kautsky, E., L. Järnberg, A. Quinlan, and P. Ryan. 2021. Wayfinder: a new generation of resilience practice. Ecology and Society 26(2):39. https://doi.org/10.5751/es-12176-260239

Engeström, Y. 2016. Studies in expansive learning: learning what is not yet there. Cambridge University Press, New York, New York, USA.

Falardeau, M., C. Raudsepp-Hearne, and E. M. Bennett. 2018. A novel approach for co-producing positive scenarios that explore agency: case study from the Canadian Arctic. Sustainability Science. https://doi.org/10.1007/s11625-018-0620-Z

Finlay, L. 2002. "Outing” the researcher: The provenance, process and practice of reflexivity. Qualitative Health Research 12 (4):531-545. https://doi.org/10.1177/104973202129120052
Folke, C., S. Carpenter, B. Walker, M. Scheffer, T. Elmqvist, L. Gunderson, and C. S. Holling. 2004. Regime shifts, resilience, and biodiversity in ecosystem management. Annual Review of Ecology, Evolution, and Systematics 35(1):557-581. https://doi. org/10.1146/annurev.ecolsys.35.021103.105711

Folke, C., T. Hahn, P. Olsson, and J. Norberg. 2005. Adaptive governance of social-ecological systems. Annual Review of Environment and Resources 30:441-73. https://doi.org/10.1146/ annurev.energy.30.050504.144511

Folke, C. 2006. Resilience: the emergence of a perspective for social-ecological systems analyses. Global Environmental Change 16(3):253-267. https://doi.org/10.1016/j.gloenvcha.2006.04.002

Folke, C., S. R. Carpenter, B. Walker, M. Scheffer, T. Chappin, and J. Rockström. 2010. Resilience thinking: integrating resilience, adaptability and transformability. Ecology and Society 15(4):20-28. https://doi.org/10.5751/ES-03610-150420

Folke, C. 2016. Resilience (Republished). Ecology and Society 21 (4):44. https://doi.org/10.5751/ES-09088-210444

Folke, C., R. Biggs, A. V. Norström, B. Reyers, and J. Rockström. 2016. Social-ecological resilience and biosphere-based sustainability science. Ecology and Society 21(3):41. https://doi.org/10.5751/ ES-08748-210341

Freeth, R., and S. Drimie. 2016. Participatory scenario planning: from scenario 'stakeholders' to scenario 'owners'. Environment: Science and Policy for Sustainable Development 58(4):32-43. https://doi.org/10.1080/00139157.2016.1186441

Friese, S. 2012. Qualitative data analysis with Atlas.ti. Sage, Los Angeles, USA.

Garmestani, A., J. B. Ruhl, B. C. Chaffin, R. K. Craig, H. F. M. W. van Rijswick, D. G. Angeler, C. Folke, L. Gunderson, D. Twidwel, and C. R. Allen. 2019. Untapped capacity for resilience in environmental law. Proceedings of the National Academy of Sciences 116(40): 19899-19904. https://www.pnas.org/content/116/40/19899 https://doi.org/10.1073/pnas.1906247116

Griffith, R., P. Ryan, G. Walkerden, and S. Robinson. 2014. Can regional communities intentionally build resilient landscapes and communities? An overview of three case studies from regional Australia. Transformation for Resilience Landscapes and Communities Partnership. https://www.ausresilience.com.au/ research/transformation.

Gunderson, L., and C. S. Holling, editors. 2002. Panarchy: understanding transformations in human and natural systems. Island Press, Washington, D.C., USA.

Gunderson, L., B. A. Cosens, B. C. Chaffin, C. A. (T.) Arnold, A. K. Fremier, A. S. Garmestani, R. K. Craig, H. Gosnell, H. E. Birge, C. R. Allen, M. H. Benson, R. R. Morrison, M. C. Stone, J. A. Hamm, K. Nemec, E. Schlager, and D. Llewellyn. 2017. Regime shifts and panarchies in regional scale social-ecological water systems. Ecology and Society 22(1):31. https://doi. org/10.5751/ES-08879-220131

Hahn, T. 2011. Self-organized governance networks for ecosystem management: who is accountable? Ecology and Society 16(2):18. https://doi.org/10.5751/es-04043-160218 
Hartvigsen, G., A. Kinzig, and G. Peterson. 1998. Use and analysis of complex adaptive systems in ecosystem science: overview of special section. Ecosystems 1(5):427-430. https://doi. org/10.1007/s100219900036

Heemskerk, M., K. Wilson, and M. Pavao-Zuckerman. 2003. Conceptual models as tools for communication across disciplines. Conservation Ecology 7(3):8. https://doi.org/10.5751/ES-00554-070308

Holland, J. 1995. Hidden order: how adaptation builds complexity. Addison-Wesley, New York, New York, USA.

Holling, C. S. 1973. Resilience and stability of ecological systems. Annual Review of Ecology and Systematics 4:1-23. https://doi. org/10.1146/annurev.es.04.110173.000245

Holling, C. S. 1986. The resilience of terrestrial ecosystems: local surprise and global change. Pages 292-317 in W. C. Clarkand and R. E. Munn, editors. Sustainable development of the biosphere: interactions between the world economy and the global environment. Cambridge University Press, Cambridge, UK.

Hopkins, R. 2008. The transition handbook: from oil dependency to local resilience. Green Book Ltd, Totnes, UK.

Hopkins, R. 2011. The transition companion: making your community more resilient in uncertain times. Chelsea Green Publishing, White River Junction, Vermont, USA.

Horcea-Milcu, A.I., B. Martín-López, D. P. Lam, and D. J. Lang. 2020. Research pathways to foster transformation: linking sustainability science and social-ecological systems research. Ecology and Society 25(1):13. https://doi.org/10.5751/ES-11332-250113

Huitric, M., G. Peterson, and J. C. Rocha. 2016. What factors build or erode resilience in the Arctic? Pages 96-125 in Arctic Council. Arctic Resilience Report. M. Carson and G. D. Peterson, editors. Stockholm Environmental Institute and Stockholm Resilience Centre, Stockholm.

Ingram, M., H. Ingram, and R. Lejano. 2015. Environmental action in the Anthropocene: the power of narrative networks. Journal of Environmental Policy \& Planning. https://doi. org/10.1080/1523908X.2015.1113513

Juarrero, A. 1999. Dynamics in action: intentional behavior as a complex system. MIT Press, Cambridge, Massachusetts, USA. https://doi.org/10.7551/mitpress/2528.001.0001

Järnberg, L., E. Enfors Kautsky, L. Dagerskog, and P. Olsson. 2018. Green niche actors navigate an opaque opportunity context: prospects for a sustainable transformation in Ethiopian agriculture. Land Use Policy 71:409-421. https://doi.org/10.1016/ j.landusepol.2017.11.053

Kurz, C. F. 2014. Working with stories in your community or organization: participatory narrative inquiry. Creative Commons, Mountain View, California, USA.

Lade, Steven J., B. Walker, and L. J. Haider. 2020. Resilience as pathway diversity: linking systems, individual, and temporal perspectives on resilience. Ecology and Society 25(3):19. https:// doi.org/10.5751/es-11760-250319

Lansing, J. S. 2003. Complex adaptive systems. Annual Review of Anthropology 32:183-204. https://doi.org/10.1146/annurev. anthro.32.061002.093440
Lam, D. P., B. Martín-López, A. Wiek, E. M. Bennett, N. Frantzeskaki, A. I. Horcea-Milcu, and D. J. Lang. 2020. Scaling the impact of sustainability initiatives: a typology of amplification processes. Urban Transformations 2(1):1-24. https://doi.org/10.1186/s42854-020-00007-9

Leach, M., I. Scoones, and A. Stirling. 2010. Dynamic sustainabilities: technology, environment, social justice. Earthscan, Abingdon, UK. https://doi.org/10.4324/9781849775069

Levin, S. A. 1998. Ecosystems and the biosphere as complex adaptive systems. Ecosystems 1(5):431-436. https://doi. org/10.1007/s100219900037

Lindow, M. 2017. Exploring resilience capacities through the art of storymaking: the case of food innovators in the Western Cape. Master thesis, Faculty of Economic and Management Sciences, Stellenbosch University.

Liu, J., T. Dietz, S. R. Carpenter, M. Alberti, C. Folke, E. Moran, A. N. Pell, P. Deadman, T. Kratz, J. Lubchenco, E. Ostrom, Z. Ouyang, W. Provencher, C. L. Redman, S. H. Schneider, and W. W. Taylor. 2007. Complexity of coupled human and natural systems. Science 317(5844):1513-1516. https://doi.org/10.1126/ science. 1144004

Millennium Ecosystem Assessment (MA). 2005. Millennium ecosystem assessment. Ecosystems and human well-being: synthesis. Island Press, Washington, D.C., USA.

Malmborg, K., E. Enfors-Kautsky, C. Queiroz, A. Norström and L. Schultz. 2020. Operationalizing ecosystem service bundles for strategic sustainability planning - a participatory approach in Southern Sweden. Ambio 50:332-334. https://doi.org/10.1007/ s13280-020-01406-9

Maru, Y., D. O’Connell, N. Grigg, N. Abel, A. Cowie, S. StoneJovicich, J. Butler, R. Wise, B. Walker, M. A. Belay, A. Fleming, S. Meharg, and J. Meyers. 2017. Making "resilience", "adaptation" and "transformation" real for the design of sustainable development projects: piloting the Resilience, Adaptation Pathways and Transformation Asssessment (RAPTA) framework in Ethiopia. CSIRO, Australia.

Meadows, D. H. 2008. Thinking in systems: a primer. D. Wright, editor. Chelsea Green Publishing, White River Junction, Vermont, USA.

Mitchell, M. 2013. From organisational learning to social learning: a tale of two organisations in the Murray-Darling Basin. Rural Society 22(3):230-241. https://doi.org/10.5172/rsj.2013.22.3.230

Mitchell, M., R. Griffith, P. Ryan, G. Walkerden, B. Walker, V. A. Brown, and S. Robinson. 2014. Applying resilience thinking to natural resource management through a "planning-by-doing" framework. Society and Natural Resources 27(3):299-314. https:// doi.org/10.1080/08941920.2013.861556

Nemec, K. T., J. Chan, C. Hoffman, T. L. Spanbauer, J. A. Hamm, C. R. Allen, T. Hefley, D. Pan, and P. Shrestha. 2014. Assessing resilience in stressed watersheds. Ecology and Society 19(1):34. https://doi.org/10.5751/ES-06156-190134

Nyström, J.-B. Jouffray, A. V. Norström, B. Crona, P. SøgaardJørgensen, S. R. Carpenter, Ö. Bodin, V. Galaz, and C. Folke. 
2019. Anatomy and resilience of the global production ecosystem. Nature 575. https://doi.org/10.1038/s41586-019-1712-3

O’Connell, D., N. Abel, N. Grigg, Y. Maru, J. Butler, A. Cowie, S. Stone-Jovicich, B. Walker, R. Wise, A. Ruhweza, L. Pearson, P. Ryan, and M. Stafford Smith. 2016. Designing projects in a rapidly changing world: guidelines for embedding resilience, adaptation and transformation into sustainable development projects. (Version 1.0). Global Environment Facility, Washington, D.C.

Olsson, P., V. Galaz, and W. J. Boonstra. 2014. Sustainability transformations: a resilience perspective. Ecology and Society 19 (4):1. https://doi.org/10.5751/ES-06799-190401

Patton, M. Q. 2002. Qualitative analysis and interpretation. Pages 431-534 in M. Q. Patton, editor. Qualitative research and evaluation methods. Third edition. Sage, Thousand Oaks, California, USA.

Pereira, L. M., T. Hichert, M. Hamann, R. Preiser, and R. Biggs. 2018. Using futures methods to create transformative spaces: visions of a good Anthropocene in southern Africa. Ecology and Society 23(1):19. https://doi.org/10.5751/ES-09907-230119

Pereira, L., N. Frantzeskaki, A. Hebinck, L. Charli-Joseph, S. Drimie, M. Dyer, H. Eakin, D. Galafassi, T. Karpouzoglou, F. Marshall, M.-L. Moore, P. Olsson, J. M. Siqueiros-García, P. van Zwanenberg, and J. M. Vervoort. 2020. Transformative spaces in the making: key lessons from nine cases in the Global South. Sustainability Science 15:161-178. https://doi.org/10.1007/ s11625-019-00749-X

Pollard, S., H. Biggs, and D. R. Du Toit. 2014. A systemic framework for context-based decision making in natural resource management: reflections on an integrative assessment of water and livelihood security outcomes following policy reform in South Africa. Ecology and Society 19(2). https://doi.org/10.5751/ ES-06312-190263

Preiser, R., R. Biggs, A. De Vos, and C. Folke. 2018. Socialecological systems as complex adaptive systems: organizing principles for advancing research methods and approaches. Ecology and Society 23(4):46. https://doi.org/10.5751/ES-10558-230446

Pretty, J. N., I. Guijt, I. Scoones, and J. Thompson. 1995. A trainer's guide for participatory learning and action. IIED, London, UK.

Queiroz, C., M. Meacham, K. Richter, A. V. Norström, E. Andersson, J. Norberg, and G. Peterson. 2015. Mapping bundles of ecosystem services reveals distinct types of multifunctionality within a Swedish landscape. Ambio 44(1):89-101. https://doi. org/10.1007/s13280-014-0601-0

Quinlan, A. E., M. Berbés-Blázquez, L. J. Haider, and G. D. Peterson. 2016. Measuring and assessing resilience: broadening understanding through multiple disciplinary perspectives. Journal of Applied Ecology 53(3):677-687. https://doi. org/10.1111/1365-2664.12550

Railsback, S. F., and V. Grimm. 2011. Agent-based and individual-based modeling: a practical introduction. Princeton university press, Princeton, New Jersey, USA.
Resilience Alliance. 2007. Assessing and managing resilience in social-ecological systems: A practitioner's workbook.

Resilience Alliance. 2010. Assessing resilience in social-ecological systems: Workbook for practitioners. Revised version 2.0.

Salomon, A. K., A. E. Quinlan, G. H. Pang, D. K. Okamoto, and L. Vazquez-Vera. 2019. Measuring social-ecological resilience reveals opportunities for transforming environmental governance. Ecology and Society 24(3):16. https://doi.org/10.5751/ES-11044-240316

Schlüter, M., and C. Pahl-Wostl 2007. Mechanisms of resilience in common-pool resource management systems: an agent-based model of water use in a river basin. Ecology and Society 12(2):4. https://doi.org/10.5751/es-02069-120204

Schoon, M., and S. van der Leeuw. 2015. The shift toward socialecological systems perspectives: insights into the human-nature relationship. Natures Sciences Sociétés 23(2):166-174. https://doi. org/10.1051/nss/2015034

Schultz, L., C. Folke, H. Österblom, and P. Olsson. 2015. Adaptive governance, ecosystem management, and natural capital. PNAS 112:7369-7374. https://doi.org/10.1073/pnas. 1406493112

Sellberg, M. M., C. Wilkinson, and G. D. Peterson. 2015. Resilience assessment: a useful approach to navigate urban sustainability challenges. Ecology and Society 20(1):43. https:// doi.org/10.5751/ES-07258-200143

Sellberg, M. M., S. Borgström, A. V. Norström, and G. D. Peterson. 2017. Improving participatory resilience assessment by cross-fertilizing the Resilience Alliance and Transition Movement approaches. Ecology and Society 22(1):28. https://doi. org/10.5751/ES-09051-220128

Sellberg, M. M., P. Ryan, S. T. Borgström, A. V. Norström, and G. D. Peterson. 2018. From resilience thinking to Resilience Planning: lessons from practice. Journal of Environmental Management 217:906-918. https://doi.org/10.1016/j.jenvman.2018.04.012

Steffen, W., Å. Persson, L. Deutsch, J. Zalasiewicz, M. Williams, K. Richardson, C. Crumley, P. Crutzen, C. Folke, L. Gordon, M. Molina, V. Ramanathan, J. Rockström, M. Scheffer, H. J. Schellnhuber, and U. Svedin. 2011. The Anthropocene: from global change to planetary stewardship. Ambio 40:739-761. https://doi.org/10.1007/s13280-011-0185-x

Sterman, J. D. 2000. Business dynamics: systems thinking and modeling for a complex world. McGraw-Hill/Irwin, New York, New York, USA.

Tengö, M., E. S. Brondizio, T. Elmqvist, P. Malmer, and M. Spierenburg. 2014. Connecting diverse knowledge systems for enhanced ecosystem governance: the multiple evidence base approach. Ambio 43(5):579-591. https://doi.org/10.1007/ s13280-014-0501-3

Tosey, P., M. Visser, and M. N. K. Saunders. 2011. The origins and conceptualizations of "triple-loop"learning: a critical review. Management Learning 43(3):291-307. https://doi. org/10.1177/1350507611426239

Waldrop, M. M. 1993. Complexity: the emerging science at the edge of order and chaos. Simon and Schuster, New York, New York, USA. https://doi.org/10.1063/1.2809917 
Walker, B. H., S. R. Carpenter, J. M. Anderies, N. Abel, G. S. Cumming, M. A. Janssen, L. Lebel, J. Norberg, G. D. Peterson, and R. Pritchard. 2002. Resilience management in socialecological systems: a working hypothesis for a participatory approach. Conservation Ecology 6(1):14. https://doi.org/10.5751/ ES-00356-060114

Walker, B., and D. Salt. 2006. Resilience thinking: sustaining ecosystems and people in a changing world. Island Press, Washington D. C., USA.

Walker, B., N. Abel, J. M. Anderies, and P. Ryan. 2009. Resilience, adaptability, and transformability in the Goulburn-Broken Catchment, Australia. Ecology and Society 14(1):12. https://doi. org/10.5751/ES-02824-140112

Walker, B., and D. Salt. 2012. Resilience practice: building capacity to absorb disturbance and maintain function. Island Press, Washington, D.C., USA. https://doi.org/10.5822/978-1-61091-231-0

Walker, B., S. R. Carpenter, C. Folke, L. Gunderson, G. D. Peterson, M. Scheffer, M. Schoon, and F. R. Westley. 2020. Navigating the chaos of an unfolding global cycle. Ecology and Society 25(4):23. https://doi.org/10.5751/es-12072-250423

Wall, T. U., A. M. Meadow, and A. Horganic. 2017. Developing evaluation indicators to improve the process of coproducing usable climate science. Weather Climate and Society 9:95-107. https://doi.org/10.1175/WCAS-D-16-0008.1

Walters, C. J. 1986. Adaptive management of renewable resources. Macmillan Publishing Company, New York, New York, USA.

Westley, F., O. Tjornbo, L. Schultz, P. Olsson, C. Folke, B. Crona, and O. Bodin. 2013. A theory of transformative agency in linked social-ecological systems. Ecology and Society 18(3):27. https:// doi.org/10.5751/ES-05072-180327

Wimsatt, W. C. 1994. The ontology of complex systems: levels of organization, perspectives, and causal thickets. Canadian Journal of Philosophy 24(sup1):207-274. https://doi.org/10.1080/004550$\underline{91.1994 .10717400}$

Wise, R. M., I. Fazey, M. Stafford Smith, S. E. Park, H. C. Eakin, E. R. M. Archer Van Garderen, and B. Campbell. 2014. Reconceptualising adaptation to climate change as part of pathways of change and response. Global Environmental Change 28:325-336. https://doi.org/10.1016/j.gloenvcha.2013.12.002

Yankelovich, D. 2001. The magic of dialogue: transforming conflict into cooperation. Simon and Schuster, New York, New York, USA.

Xu, L., D. Marinova, and X. Guo. 2014. Resilience thinking: a renewed system approach for sustainability science. Sustainability Science 10:123-138. https://doi.org/10.1007/s11625-014-0274-4 


\section{Appendix 1. Assessment questions}

We operationalized the complexity framework (Table 3) by adding a set of guiding questions for assessing the cases (Table A1).

Table A1. Guiding questions for assessing how cases of resilience practice engaged with complexity.

\begin{tabular}{|c|c|}
\hline Features of CAS & Guiding questions \\
\hline 1. Contextual & $\begin{array}{l}\text { How did you make the framework/framing of the assessment relevant for } \\
\text { the particular context? } \\
\text { Did you deal with the possibility of multiple valid descriptions and } \\
\text { framings? If yes, how? } \\
\text { Did you consider your own role in shaping the outcomes? If yes, how? }\end{array}$ \\
\hline 2. Open & $\begin{array}{l}\text { How did you capture and deal with cross-scale interactions, external } \\
\text { drivers, and teleconnections - both in the process and in the analysis? } \\
\text { How did you delineate the system, and why? }\end{array}$ \\
\hline 3. Relational & $\begin{array}{l}\text { What relations did you build through the assessment process/resilience } \\
\text { interventions (e.g. through who you collaborated with)? And were there } \\
\text { any specific things you did that were useful in fostering dialogue and } \\
\text { building relations? } \\
\text { What relations between components in the system were you considering } \\
\text { explicitly in the analysis? Was there any specific framework or method } \\
\text { that was useful in capturing those relations? }\end{array}$ \\
\hline 4. Dynamic & $\begin{array}{l}\text { Did you capture dynamics over time, and e.g. potential } \\
\text { regimes/thresholds, and feedback loops? Any specific approach or method } \\
\text { that you found useful? }\end{array}$ \\
\hline 5. Adaptive & $\begin{array}{l}\text { How did you build in flexibility and learning in the assessment process to } \\
\text { deal with unexpected shocks /responses? } \\
\text { How did the process foster adaptive responses and/or learning } \\
\text { experiences? }\end{array}$ \\
\hline 6. Emergent & $\begin{array}{l}\text { Were there any emergent, unplanned outcomes (positive or negative) of } \\
\text { the assessment process (e.g. better relations between people that did not } \\
\text { speak to each other before, more trust, activating different networks)? } \\
\text { And how did you deal with them? }\end{array}$ \\
\hline
\end{tabular}




\begin{tabular}{|l|l|}
\hline $\begin{array}{l}\text { How did you allow for emergence (e.g. putting certain conditions in } \\
\text { place, or designing a process that allowed for new interactions and } \\
\text { novelty)? }\end{array}$ \\
\hline
\end{tabular}

To better understand the background of each case, and capture reflections about the case and the approach used, we added a set of general questions:

- What was the rationale/purpose for choosing this approach for this context?

- In what other types of contexts would you recommend using this approach? (were there any requirements for using this approach? e.g., of data, or participation)

- What are the advantages of this approach?

- What are the disadvantages of this approach?

- What was most useful in enabling you to better deal with complexity? (e.g., concept, tool, engagement strategy, or something else that helped unlock the case)

- Were there things you did that usefully addressed two or more of these features (1-6)?

- What do you see, in the end, as the most important contribution of your assessment/process? 


\section{Appendix 2. Tools and concepts}

Examples of the tools and concepts used by the cases when engaging with different aspects of complexity.

\section{Tools and concepts for identifying external drivers and cross-scale interactions}

External drivers and cross-scale interactions were identified during different types of exercises, for example, when developing historical timelines, systems diagrams, state-and-transition models, when defining system boundaries, or in specific scoping exercises. Approaches used in scoping exercises were e.g. SWOT-analysis, which identifies strengths, weaknesses, opportunities, and threats, and V-STEEP, which captures factors of systems or contexts across six dimensions: values, social, technological, ecological, economic, and political (Biggs and Rogers 2003, Pollard et al. 2014). Scales above and below the focal system were sometimes included in, for example, historical timelines and systems diagrams (e.g., Eskilstuna, Shyamnagar, Limpopo).

\section{Tools and concepts for mapping relations}

To conceptualize people-biosphere connections, cases mapped bundles of ecosystem services within their region (e.g., Helge å), developed systems diagrams of social-ecological systems (e.g., Pacific herring, Shyamnagar) and of how different system components influence each other (e.g., Limpopo, Helge å), and used interactive workshop exercises that illustrated connections (e.g., ALH). To describe social-ecological systems, some used frameworks and heuristics, such as ecosystem services and human well-being as defined in the Millennium Ecosystem Assessment (MA 2005) (e.g., Eskilstuna) or "the 3 L's": Landscapes, Livelihoods, and Lifestyles (e.g., Ethiopia, Murray, Helge å).

To map relations between actors, cases used e.g., social network analysis (e.g., Tajikistan, Murray), and focus group discussions (Shyamnagar). Limpopo used the Cultural Historical Activity Theory (CHAT) (Engeström 2016). CHAT offers different tools to explore issues collaboratively with actors, including a heuristic of an "activity system". Limpopo used this to tease out the different roles, responsibilities and connections between actors at different levels of governance in a "non-threatening way".

\section{Tools and concepts for facilitating dialogue and enhancing learning}

To facilitate dialogue and enhance learning in workshops, cases used social learning processes (e.g. Limpopo, Murray) (e.g., Brown and Lambert 2013, Engeström 2016), collaborative development of causal loop diagrams (e.g., Limpopo, Helge å), interactive workshop exercises (e.g. ALH) (see e.g., Hopkins 2008:60), discussions in small groups with people with different backgrounds and perspectives, and by establishing "ground rules" of listening and respecting different perspectives (e.g., Eskilstuna) (informed by Yankelovich 2001).

The Australian organizations incorporated ideas of 'triple-loop' learning (Tosey et al. 2011), adaptive management (Walters 1986) and adaptive governance (Folke et al. 2005) into their organizations, as part of building a learning culture (Mitchell 2013, Sellberg et al. 2018).

\section{Tools and concepts for assessing system dynamics}

Historical timelines have been used to identify, discuss and visualize different eras, trends, drivers of change, events, transformations, and changes in resilience and adaptive capacity over 
time (see Resilience Alliance 2010). In some cases, the timeline was part of describing the system, rather than assessing resilience and provided important context (e.g., Helge å, Shyamnagar). The time span was usually more than a hundred years back.

Tools and heuristics to facilitate workshops discussions of potential thresholds, alternate system states (current, desirable, undesirable) and what could drive system change, included: state-and-transition diagrams (Ethiopia, Murray, Kangaroo Island), the "ice-cream-diagram" (Murray) and other types of interactive workshop exercises (Eskilstuna, ALH). The ice-cream diagram is a heuristic used to discuss the current situation (bottom of the ice-cream cone) the vision or aspirations (the ice-cream), and the potential thresholds and limits of a desirable development trajectory towards the vision (the edges of the ice-cream cone). Two cases reviewed documented regime shifts in the scientific literature and the regime shifts database (http://www.regimeshifts.org) to identify potential thresholds relevant for their context (Eskilstuna, Arctic). Limpopo and Goulburn-Broken were informed by the approach of strategic adaptive management (Biggs and Rogers 2003) and used the idea of thresholds to set monitoring and management goals as ranges, rather than exact targets.

Systems diagrams include influence diagrams, causal loop diagrams and conceptual systems models. Conceptual systems models illustrate how different parts of the system are related to each other. Influence diagrams emphasize which components influence which, using boxes and arrows (Heemskerk et al. 2003). Causal loop diagrams expand on this by specifying the kind of interactions and identifying potential reinforcing and dampening feedback loops (Sterman 2000).

Different approaches to developing scenarios were: adaptation pathways (Wise et al. 2014) (Kangaroo Island, Ethiopia), downscaling of national scenarios (Kangaroo Island), combining two drivers in a scenario cross (Shyamnagar, Kangaroo Island), the ice-cream diagram explained above (Helge å), and "Seeds of a Good Anthropocene" (Pereira et al. 2018) (Helge å).

\section{Theory-based resilience frameworks}

Resilience frameworks that are based on theory make it easier to translate between cases and to compare them. The theory-based frameworks used by the cases in this paper were primarily based on social-ecological resilience theory. However, the frameworks adopted related but different aspects of this body of theory. The most common frameworks used by the cases in this study were the seven resilience principles (Biggs et al. 2015) (Pacific herring, Eskilstuna, ALH, Goulburn-Broken) and the four categories of resilience-building strategies (Berkes et al. 2003) (Arctic, Shyamnagar). Other frameworks used were: five capitals of adaptive capacity (Murray) and nine characteristics of resilient systems (Walker and Salt 2006) (Limpopo). 


\section{Appendix 3. Main strategies for engaging with complexity with supporting examples from cases}

Table 3A. Strategies for engaging with complexity. Examples from the twelve cases included in this study (Table 2). Complexity is addressed through a framework of six features (Table 3).

\begin{tabular}{|c|c|}
\hline $\begin{array}{l}\text { Features of } \\
\text { CAS }\end{array}$ & Main strategies and examples from cases \\
\hline 1. Contextual & 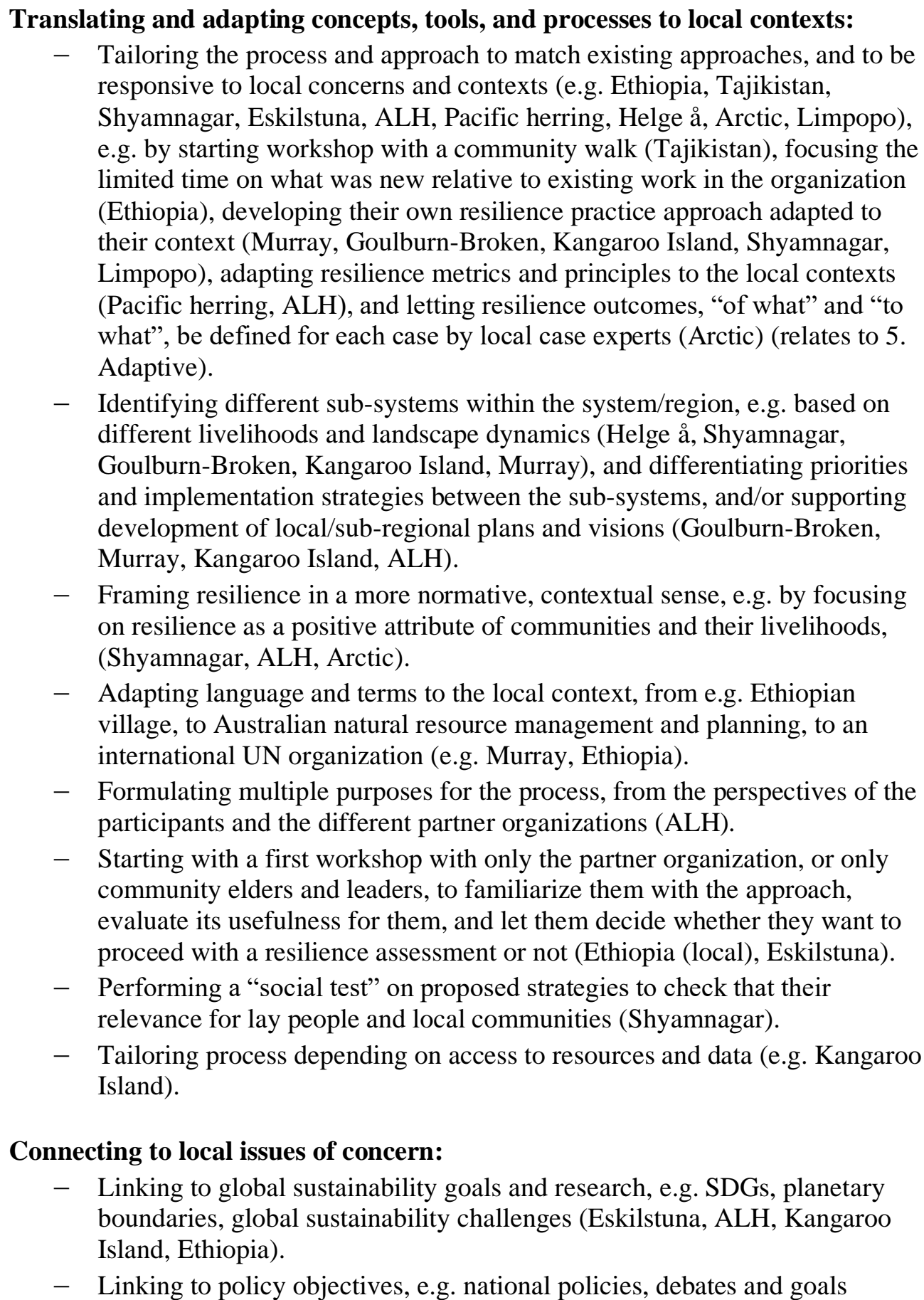 \\
\hline
\end{tabular}




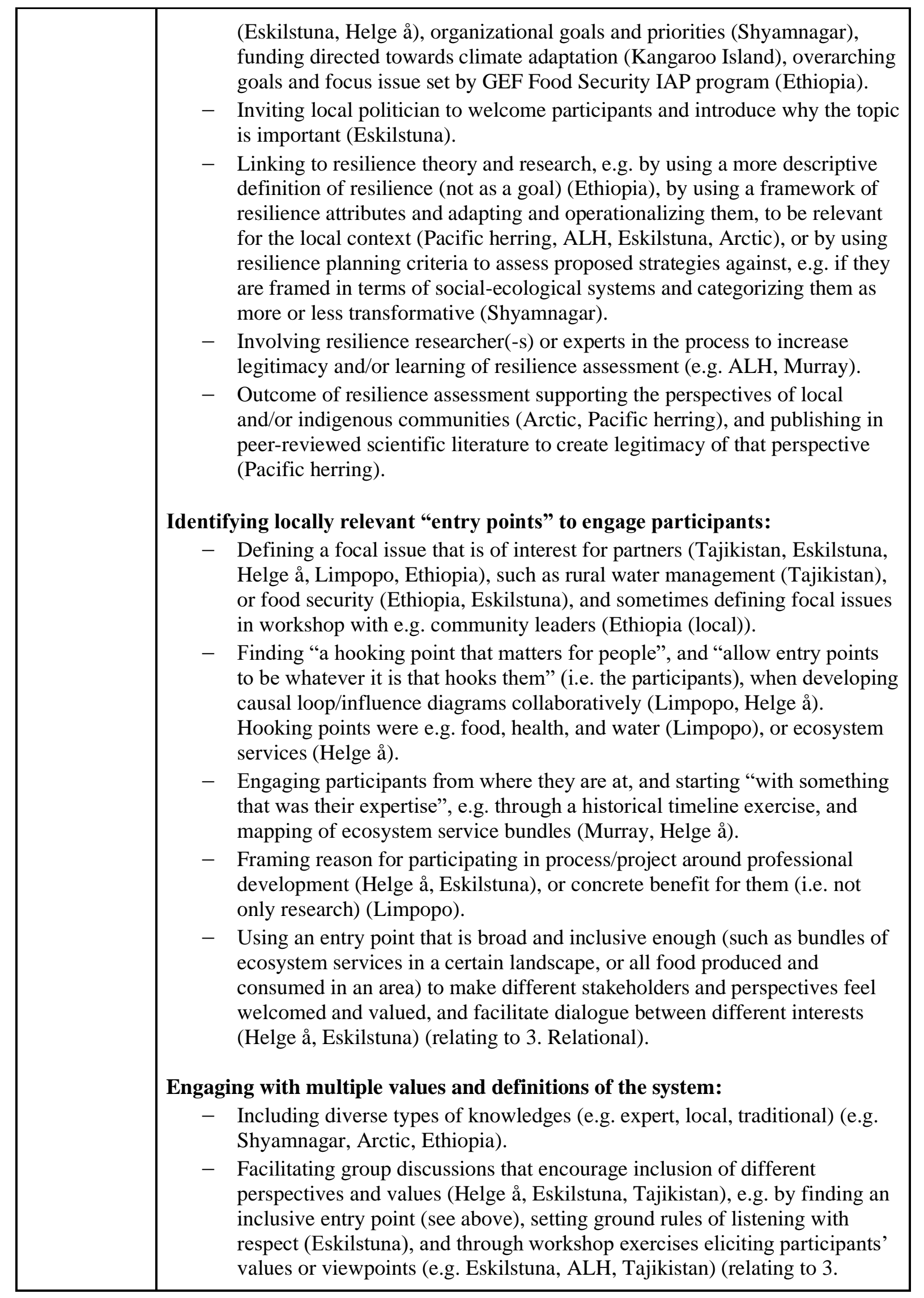




\begin{tabular}{|c|c|}
\hline & 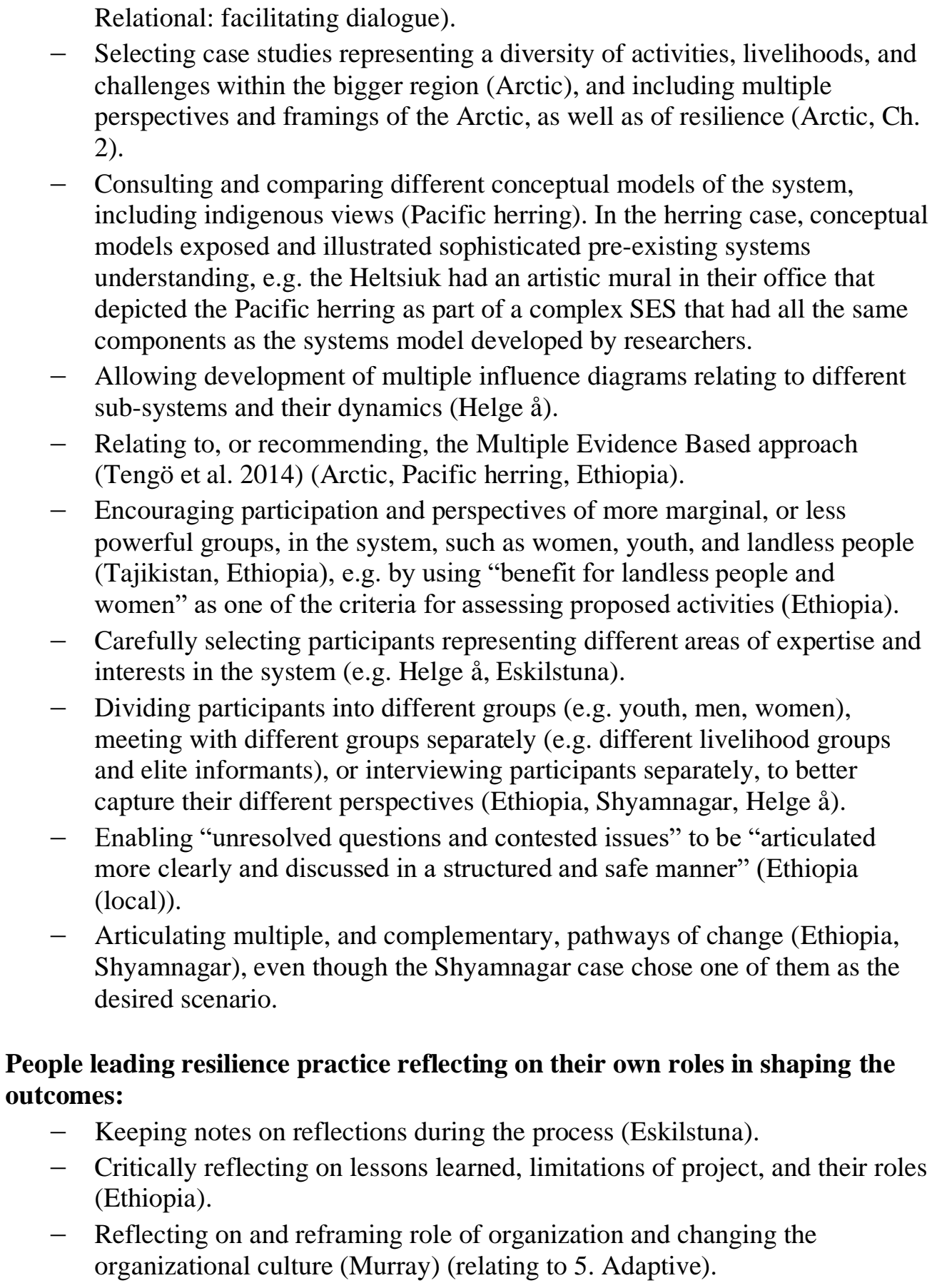 \\
\hline 2. Open & $\begin{array}{l}\text { Finding a useful way of defining the boundaries of the focal system: } \\
\text { - Using the administrative boundaries of the municipality (Eskilstuna), or the } \\
\text { catchment management authority (Goulburn-Broken, Murray, Kangaroo } \\
\text { Island), or "a region that loosely corresponded to the traditional territory } \\
\text { (including fishing areas) of the Heltsiuk First Nation" (Pacific herring). } \\
\text { - Focusing on the community or village and its surroundings, or people's } \\
\text { livelihoods, as a system (ALH, Ethiopia, Arctic). }\end{array}$ \\
\hline
\end{tabular}


- Using a mix of administrative boundaries, and biophysical boundaries (e.g. a protected forest, a river, a catchment) to define the system spatially (Shyamnagar, Limpopo, Helge å), and these boundaries are only partially overlapping (Limpopo, Helge å).

- Including scales above (and below) the focal system in e.g. historical timeline, conceptual model of system, or influence diagram (Eskilstuna, Shyamnagar, Limpopo), or excluding external drivers in the systems diagram (Helge å).

- Identifying sub-systems, or "local landscapes" within their regions, that have fuzzy and partly overlapping geographical boundaries, and are defined by both social and ecological factors (e.g. livelihoods, landscapes, and lifestyles) (Murray, Kangaroo Island, Goulburn-Broken).

- Bounding the system is used as an exercise, or key tool, with participants (Shyamnagar, Limpopo).

- Using key issues to help define the system boundaries (e.g. Limpopo, Shyamnagar, Eskilstuna).

- Focusing on the perceived sphere of influence (Limpopo, Helge å).

- Spatial boundaries were also driven by the scale and resolution of accessible data, and different boundaries were used for different variables (Helge å).

- Target regions/states and project sites were set by GEF's Food Security IAP program, which the resilience assessment was part of (Ethiopia, national).

- Acknowledging that place is tightly linked to cultural identity and heritage (Pacific herring, Shyamnagar).

- System definitions were defined in each case (Arctic), but the overarching geographical boundary was the Arctic council countries, even though acknowledging multiple definitions of the Arctic (Ch. 2).

- Including cases in the "wide present" or present day (Arctic).

- Including the main events and policies that shaped the system from 1960's and onwards (Shyamnagar).

- The time span of timelines were usually more than a hundred years back (Eskilstuna, Pacific herring, Shyamnagar).

\section{Identifying external drivers of change and interactions across scales:}

- Exploring external drivers and events over time, e.g. by including and discussing them in the historical timeline exercise (Eskilstuna, Helge å, Shyamnagar), or by exploring their influence over different time periods (Pacific herring).

- Identifying potential drivers, or threats (and opportunities), with participants (Eskilstuna, ALH, Helge å), based on a kind of SWOT-analysis (Strengths, Weaknesses, Opportunities, Threats) (Eskilstuna, ALH), or using V-STEEP (incl. values, social, technological, economic, environmental, and politicolegal) (Limpopo).

- Introducing a set of global challenges motivating a need to transition to sustainability (incl. climate change, ecosystem integrity, income inequality, etc.) in workshop exercise where participants presented "context cards" with facts to each other in small groups (ALH).

- Facilitating group discussions of consequences of drivers for focal system or community values (Eskilstuna, ALH). 


\begin{tabular}{|c|c|}
\hline & $\begin{array}{l}\text { - Including external drivers in influence/causal loop diagrams (Ethiopia, } \\
\text { Limpopo). } \\
\text { - } \\
\text { Including scales above and below the focal system, and interventions and } \\
\text { drivers on different scales, as part of the general systems model of the SES } \\
\text { (Shyamnagar). } \\
\text { - } \text { Including (external) drivers in state-and-transition models (Kangaroo Island, } \\
\text { Murray, Ethiopia). } \\
\text { - } \text { Including cross-scale linkages and external drivers (e.g. climate change, } \\
\text { larger scale political economy, global and regional economics) as part of } \\
\text { bounding the system (Limpopo). } \\
\text { - } \text { Identifying key drivers of change for their region, or different global and } \\
\text { national trends and their implications, in their resilience-based plans } \\
\text { (Goulburn-Broken, Kangaroo Island), and mentioning change in drivers as } \\
\text { part of what could trigger a review of the plan (Goulburn-Broken). } \\
\text { - } \text { Identifying climate change, or "climate variability", as a key driver of } \\
\text { change (e.g. Kangaroo Island, Murray, Goulburn-Broken, Arctic), } \\
\text { sometimes driven by funding for climate change adaptation (Kangaroo } \\
\text { Island). } \\
\text { - Drivers were included in each of the reviewed cases, identified from the } \\
\text { case perspective (including e.g. mining, socio-political changes, resource } \\
\text { change, climate change) (Arctic). } \\
\text { - Discussing connections between cases in their region, and between cases } \\
\text { and higher scales, through e.g. regime shifts, or drivers of change (Arctic). } \\
\text { Engaging key higher levels of governance and external actors who shape } \\
\text { system context and dynamics: } \\
\text { - } \text { Involving actors across scales or organizational levels (e.g. municipality, } \\
\text { county, national), or higher-level actors relative to the focal scale, in the } \\
\text { participatory process (Helge å, Eskilstuna, ALH, Ethiopia (national)). } \\
\text { - Having separate meetings with higher-level governance actors relative to } \\
\text { the focal scale (Ethiopia (local)). } \\
\text { - Identifying higher-level governance (e.g. actors, institutions, capacity, } \\
\text { networks) as critical levers of change (Arctic, Pacific herring, Ethiopia). }\end{array}$ \\
\hline 3. Relational & $\begin{array}{l}\text { Building relations between science and practice and integrating different } \\
\text { disciplines and types of knowledge: } \\
\text { - } \quad \text { Engaging with people and knowledges, across disciplines (e.g. natural and } \\
\text { social), and across research and practice (All the cases: i.e. Arctic, Pacific } \\
\text { Pacific herring, Tajikistan, Ethiopia, Shyamnagar, Eskilstuna, LSS, Helge å, } \\
\text { Murray, Goulburn-Broken, Kangaroo Island, Limpopo). } \\
-\quad \text { Using the concept of social-ecological systems to integrate different } \\
\text { disciplines and types of knowledges (e.g. Arctic, Shyamnagar, Murray, } \\
\text { Goulburn-Broken, Kangaroo Island). } \\
-\quad \text { Researchers and practitioners working together to design and perform the } \\
\text { process (e.g. Eskilstuna, ALH, Murray, Tajikistan). } \\
-\quad \text { Using bridging individuals (e.g. case experts in Arctic case, resilience } \\
\text { expert in the Australian cases and Shyamnagar, research communicator in } \\
\text { Eskilstuna case) and organizations (e.g. Ethiopia, Arctic) to help bridge }\end{array}$ \\
\hline
\end{tabular}




\begin{tabular}{|c|}
\hline 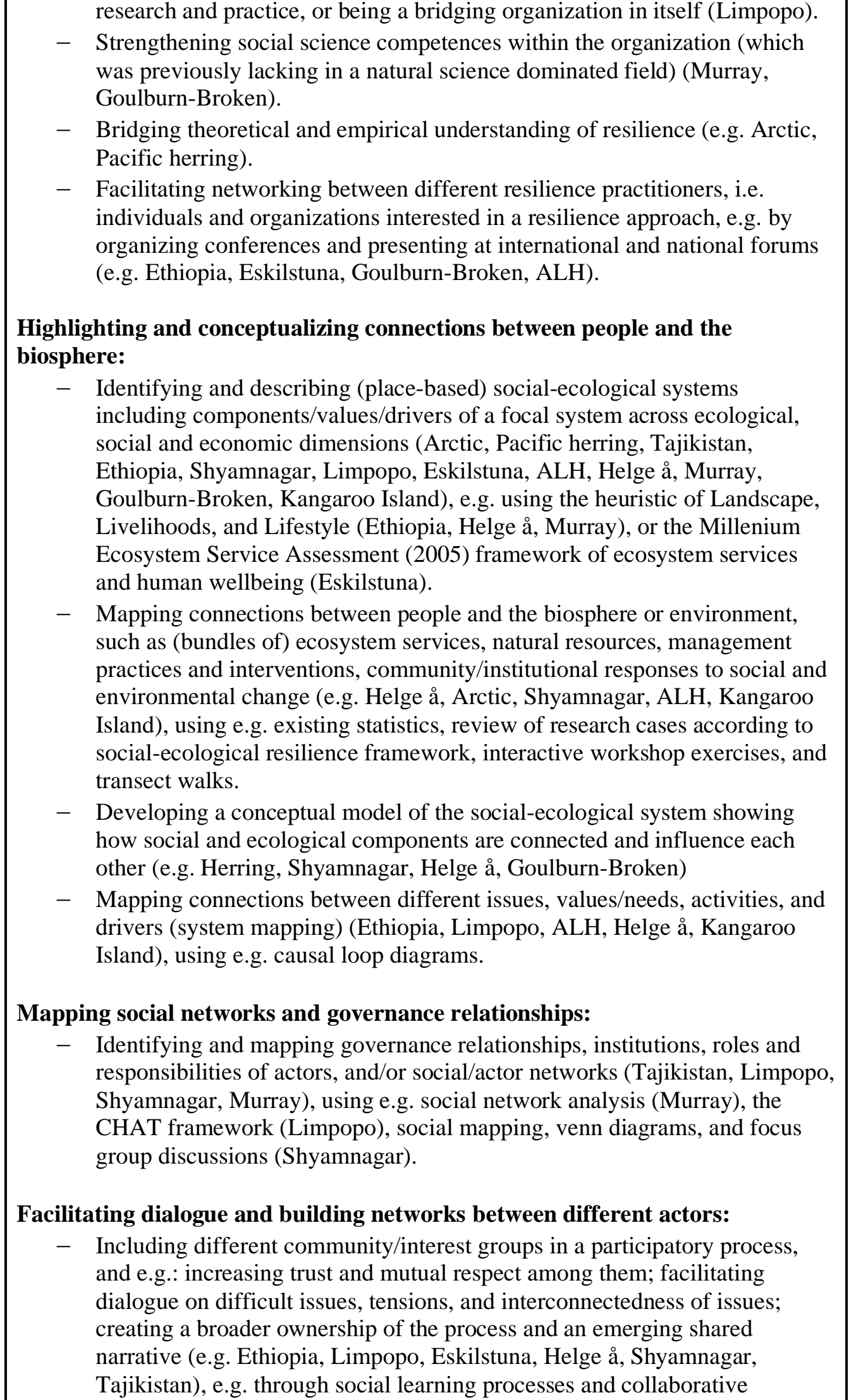 \\
\hline
\end{tabular}




\begin{tabular}{|c|c|}
\hline & $\begin{array}{l}\text { development of causal loop diagrams (Limpopo), and using small, diverse } \\
\text { groups, and establishing "ground rules" of listening and respecting different } \\
\text { perspectives (Eskilstuna). } \\
\text { - } \\
\text { Building bridges between divides of different groups of people, e.g. more } \\
\text { interested in sustainability vs. more traditional forms of development (in } \\
\text { their organizations and among residents) (e.g. ALH, Kangaroo Island), and } \\
\text { different sectors within an organization, e.g. sustainable development and } \\
\text { crisis management (Eskilstuna). } \\
\text { - } \\
\text { Building relations and networks between the actors leading the resilience } \\
\text { practice and local actors, communities, and partners (e.g. Pacific herring, } \\
\text { Shyamnagar), e.g. through facilitating local-level planning (ALH, Murray, } \\
\text { Goulburn-Broken, Kangaroo Island), creating a community council (incl. } \\
\text { previous critics of their organization) and devolving responsibility of } \\
\text { developing the resilience-based plan to them, and strengthening capacity of } \\
\text { actor networks (Murray), mapping community values and going through a } \\
\text { major consultation with community and partners in developing the } \\
\text { resilience-based plan employing multiple engagement techniques } \\
\text { (Goulburn-Broken, Kangaroo Island), by "not coming from only a research } \\
\text { perspective", but also "working with them on a concrete project", through } \\
\text { the organization having worked in the area for several years, and by projects } \\
\text { being part of longer-term programs and becoming more of an ongoing } \\
\text { process (Limpopo). } \\
\text { Bringing actors together to develop coordinated actions: } \\
\text { The organization/actor itself taking on a leadership role of bringing different } \\
\text { actors together, e.g. to articulate common objectives and coordinate efforts } \\
\text { to reach them (e.g. Goulburn-Broken, Murray, Kangaroo Island), develop } \\
\text { collaborative projects and building trust around a common practice (e.g. } \\
\text { Limpopo), develop a joint action plan (e.g. Eskilstuna, Helge å), and source } \\
\text { funding (e.g. Goulburn-Broken, Shyamnagar). }\end{array}$ \\
\hline 4. Dynamic & $\begin{array}{l}\text { Identifying historical changes and trends: } \\
\text { - } \text { Developing a historical timeline, with participants and/or other data sources } \\
\text { (e.g. Eskilstuna, Pacific herring, Tajikistan, Shyamnagar, Murray, } \\
\text { Goulburn-Broken, Kangaroo Island, Limpopo, Helge å), which e.g. has } \\
\text { been used to identify, discuss, and visualize different eras, trends, drivers of } \\
\text { change, events, transformations, and changes in resilience and adaptive } \\
\text { capacity over time. Some cases used other frameworks and heuristics to } \\
\text { explore and analyze timelines, e.g. the adaptive cycle, or adaptation } \\
\text { pathways (Goulburn-Broken, Kangaroo Island, Limpopo). } \\
\text { - } \text { Including a historical perspective on how system interactions and } \\
\text { components have changed over time, e.g. through workshop exercise } \\
\text { (ALH), or through developing causal loop diagrams for different eras } \\
\text { (Limpopo), which were useful for enhancing system understanding (5. } \\
\text { Adaptive), and facilitating dialogue among participants (3. Relational). } \\
\text { - Assessing how different general resilience attributes have changed over } \\
\text { time (i.e. over three management eras), illustrated using spider diagrams } \\
\text { (Pacific herring). } \\
\text { - } \\
\text { Looking backwards at the near history of } 19 \text { cases and investigating } \\
\text { resilience outcomes so far (i.e. loss, maintenance, or transformation) }\end{array}$ \\
\hline
\end{tabular}




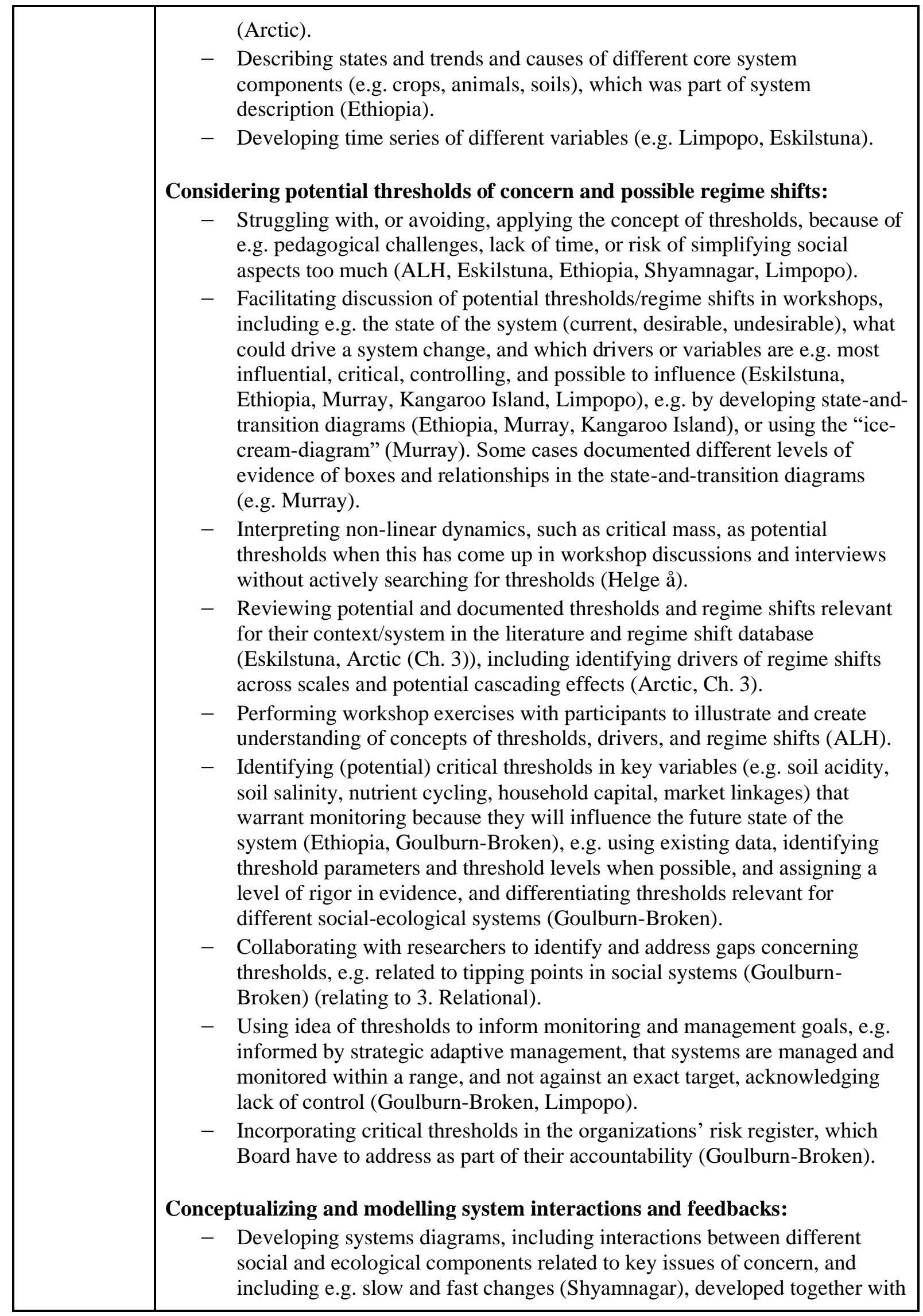




\begin{tabular}{|c|c|}
\hline & 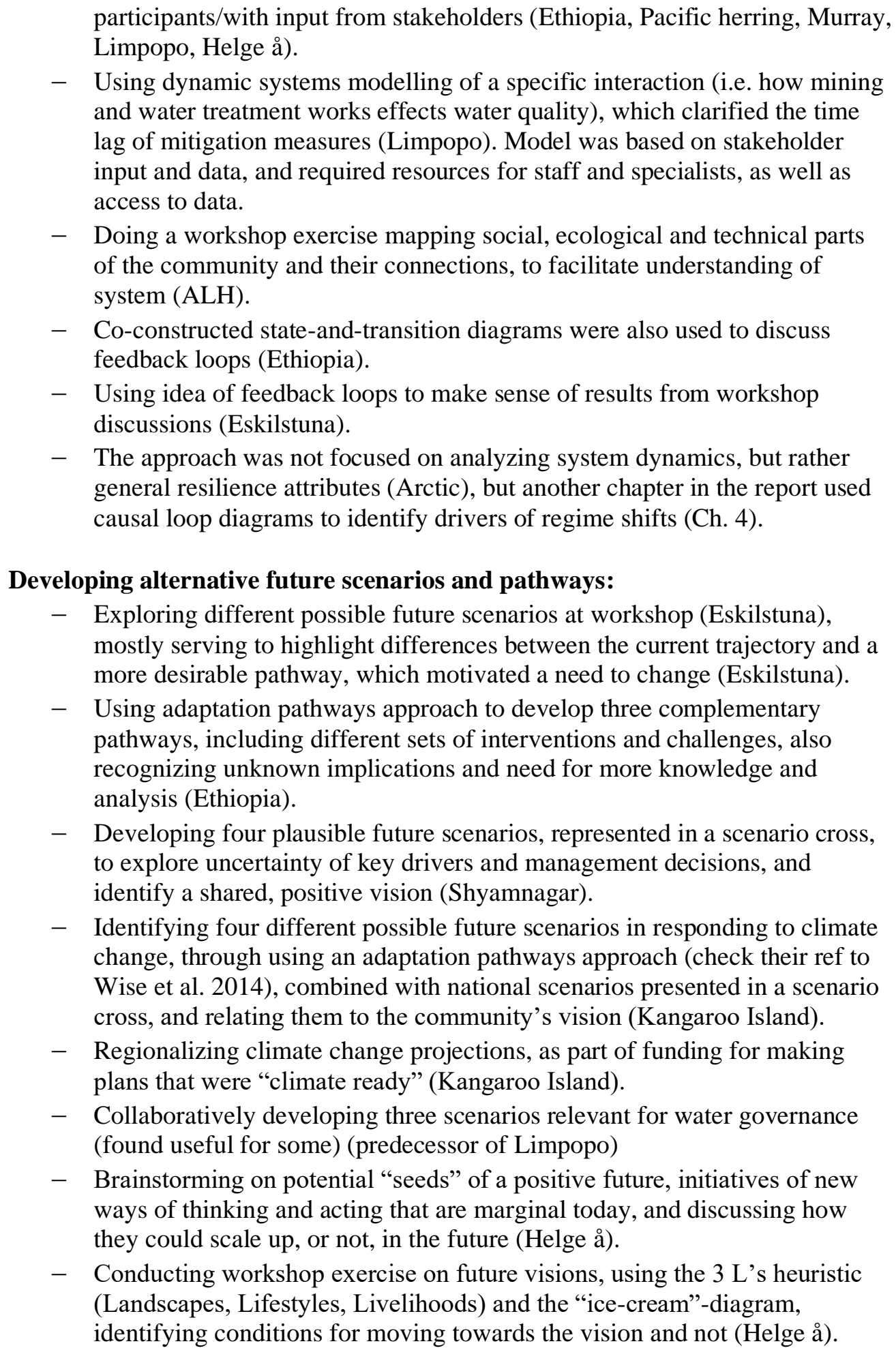 \\
\hline 5. Adaptive & $\begin{array}{l}\text { Designing a flexible and iterative process: } \\
-\quad \text { Adapting the workshop process, format, focal issue, or participants, or } \\
\text { adapting the engagement strategy, during the course of the process } \\
\text { (Eskilstuna, ALH, Murray, Goulburn-Broken, Helge å), e.g. by adding }\end{array}$ \\
\hline
\end{tabular}




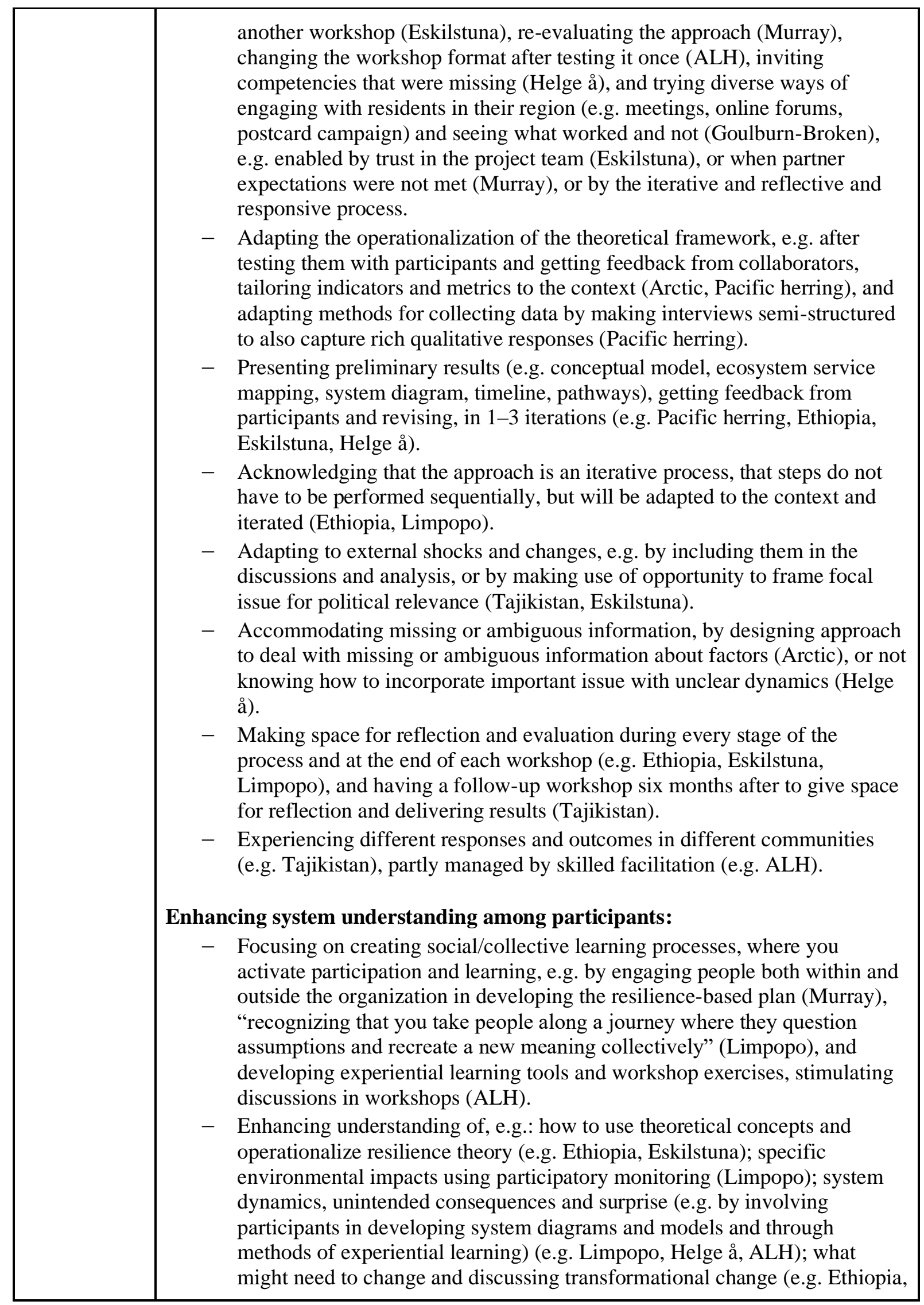


- Building capacity of community in planning, monitoring, evaluation and learning, e.g. by outlining a learning framework and engaging them in the resilience planning process (Ethiopia)

- Using process outputs (e.g. ToC, system description, system assessment, options and pathways, conceptual models, assumptions) as a basis for monitoring, evaluation, and adaptive management (Ethiopia, Shyamnagar, Kangaroo Island, Goulburn-Broken, Murray).

- Strengthening capacity of actor networks (Murray), building learning networks in different arenas, and supporting community-based monitoring of certain issues using apps (Limpopo).

- Facilitating/supporting local-level planning (in local landscapes, socialecological systems, or communities) within their regions (GoulburnBroken, Murray, Kangaroo Island, ALH).

- Devolving responsibility of developing resilience-based plan to a community committee (Murray).

- Encouraging stakeholders to make space for reflection and evaluation (Limpopo).

- Learning in the sense of professional development in the leading partners, e.g. in resilience thinking, how to apply resilience assessment and operationalize resilience principles to a specific context (e.g. ALH, Eskilstuna, Ethiopia).

\section{Using theory-based resilience assessment framework:}

- Assessing general resilience attributes in a social-ecological system using qualitative and quantitative data, showing how certain attributes are important for resilience (Arctic), how they have been eroded over time (Pacific herring), and how they could change under different scenarios (Limpopo).

- Using framework of general resilience attributes/principles, or adaptive capacity to, e.g. in local scale planning (Goulburn-Broken, Murray, ALH), to e.g. organize results from the resilience assessment process (Shyamnagar, ALH, Eskilstuna), evaluate actions and projects (existing and potential) in workshops with participants (Eskilstuna, ALH), and assess the adaptive capacity of communities in community workshops (Murray).

- Using and adapting frameworks of: seven resilience principles (Biggs et al. 2015) (Pacific herring, Eskilstuna, ALH, Goulburn-Broken), four categories of resilience-building strategies (Berkes et al. 2003) (Arctic, Shyamnagar), five capitals of adaptive capacity (Murray), and characteristics of resilient systems (Walker and Salt 2006) (Limpopo).

- Identifying different climate adaptation pathways and highlighting need to stay in an "adaptive space" where options are kept open, and where there are less negative impacts btw actions in different sectors/systems (Kangaroo Island).

- Recommending enhancing certain attributes of general resilience, such as diversity, social learning, and knowledge networks (Arctic), and highlighting potential leverage points for a governance transformation (Pacific herring). 


\begin{tabular}{|c|c|}
\hline 6. Emergent & 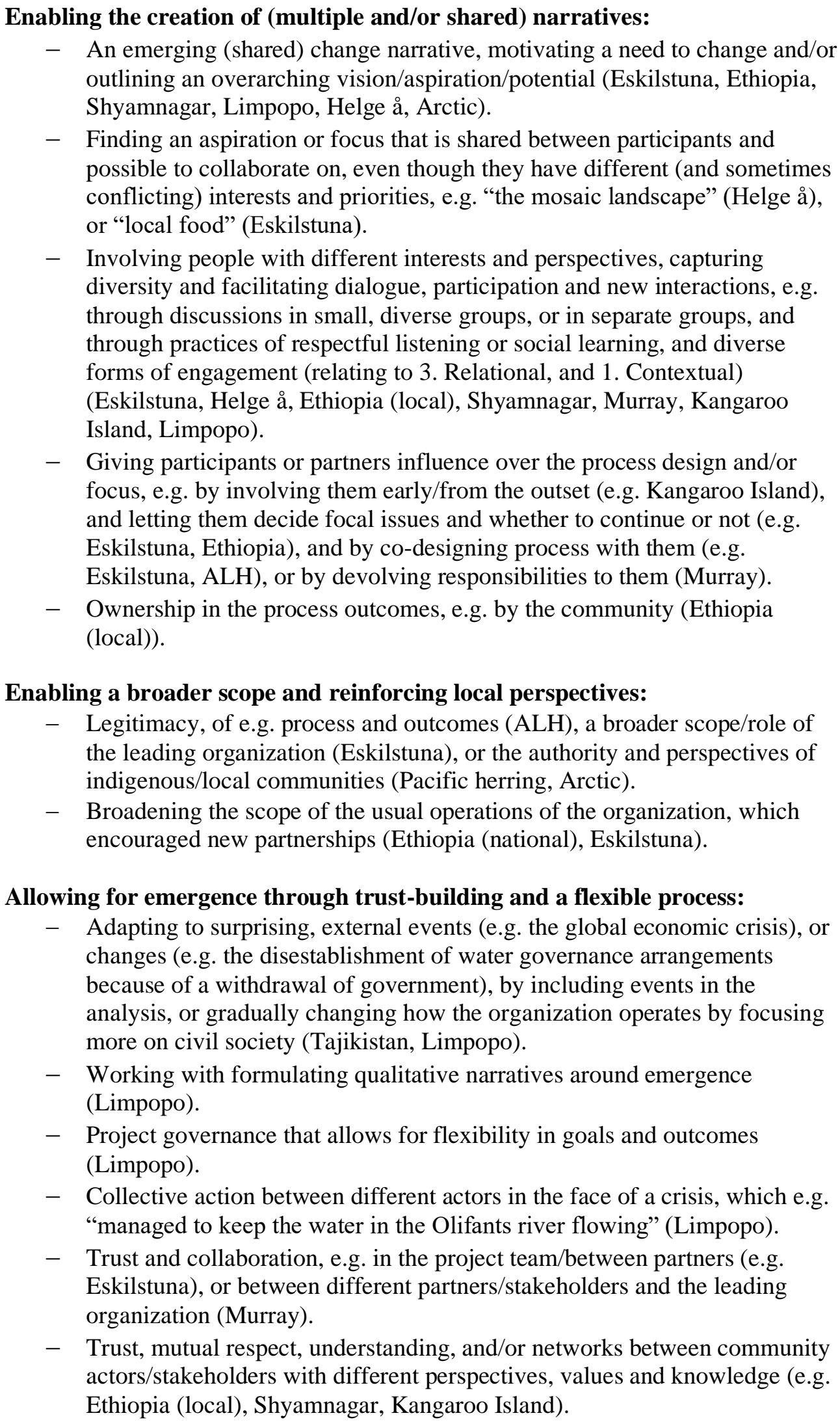 \\
\hline
\end{tabular}


- Arranging a separate meeting to discuss contested issues that arose (Ethiopia (local)).

- Providing participants with a space to reflect, think more long-term, and discuss possibilities, compared to the everyday, short-term focus (Ethiopia (local), Helge å).

- A flexible process design, allowing for iterations, changes, experimentation, and space for reflection, and adaptations to context and participant responses during the process (relating to 5. Adaptive, and 1. Contextual) (Eskilstuna, Helge å, ALH, Ethiopia (local), Limpopo).

- Experiencing having too little time for iterations (ALH), workshop exercises not working well and as anticipated, because of e.g. unclear intent and difficult terms (i.e. not adapting to local context) (Eskilstuna), organizational procedures limiting "the time and flexibility available to try a new approach and allow extensive local participation." (p. 46) (Ethiopia (national)), and using methods that were not really designed to allow for new interactions or novelty, e.g. Pacific herring case was more about validating existing knowledge, to give more legitimacy to the Heltsiuk First Nation's authority over their traditional territory, and "allowed for small surprises to be revealed".

- Trust and relations between partners and actors, and also funders (relating to 3. Relational) (Eskilstuna, ALH, Limpopo).

- Building a culture of learning and reflection into the organization/project and way of operating, through e.g. adaptive governance, adaptive management, and strategic adaptive management (e.g. Murray, Limpopo, Kangaroo Island, Goulburn-Broken, Ethiopia). 